\title{
Synthesis and characterization of $\mathrm{Ag}$-delafossites $\mathrm{AgBO}_{2}$ (B: Al, Ga, In) from rapid hydrothermal process
}

Leon Zwiener ${ }^{[a]}$, Travis Jones ${ }^{[a]}$, Elisabeth Hannah Wolf ${ }^{[a]}$, Frank Girgsdies ${ }^{[a]}$, Milivoj Plodinec ${ }^{[a, b]}$, Alexander Yu. Klyushin ${ }^{[a, c]}$, Elena Willinger ${ }^{[a]}$, Frank Rosowski ${ }^{[d, e]}$, Robert Schlög[ ${ }^{[a, f]}$ and Elias Frei ${ }^{*[a]}$

[a] Dr. L. Zwiener, Dr. T. Jones, E. H. Wolf, Dr. F. Girgsdies, Dr. M. Plodinec, Dr. A. Y. Klyushin, Dr. E. Willinger, Prof. Dr. R. Schlögl, Dr. E. Frei

Department of Inorganic Chemistry, Fritz-Haber-Institut der Max-Planck-Gesellschaft, Faradayweg 4-6, 4195 Berlin,

(Germany).

E-mail: efrei@fhi-berlin.mpg.de

[b] Dr. M. Plodinec

Division of Material Physics, Boskovic Institute, Bijenička cesta 54, 10000 Zagreb (Croatia).

[c] Dr. A. Y. Klyushin

Division of Energy Material, Helmholtz-Zentrum Berlin für Materialien und Energie GmbH, Albert-Einstein-Str. 15,

12489 Berlin (Germany).

[d] Dr. F. Rosowski

BasCat - UniCat BASF Joint Lab, Technische Universität Berlin, Hardenbergstraße 36, 10623 Berlin (Germany).

[e] Dr. F. Rosowski, Process Research and Chemical Engineering, Process Catalysis Research

BASF SE, Ludwigshafen (Germany).

[f] Prof. Dr. R. Schlögl, Department of Heterogeneous Reactions, Max-Planck-Institut für Chemische

Energiekonversion Stiftstrasse 34 - 36, Mülheim an der Ruhr, 45470 (Germany).

\begin{abstract}
A single-step rapid hydrothermal low-temperature process for the formation of high purity polycrystalline Ag-based delafossite oxides $3 \mathrm{R}-\mathrm{AgBO} 2(\mathrm{~B}: \mathrm{Al}, \mathrm{Ga}, \mathrm{In})$ is reported. For the synthesis process reusable and widely available PTFE-lined pressure vessels are used. The presence of an elemental Ag by-phase is traced back to the metastability of the Ag-delafossite under reaction conditions. High purity products are obtained by decreasing the synthesis time requirements by up to $90 \%$. The effect of the isoelectronic $B$-site atoms on the structure and bonding situation were comparatively studied experimentally and by ab-initio calculations. Distorted coordination environments are observed in all cases and the nature of the chemical bond changes qualitatively along the series of group $13 \mathrm{~B}$-site atoms Al, $\mathrm{Ga}$ and In. This is reflected in systematic changes of the (optical) band gap, the contactless conductivity, the thermal stability and the energetic position of Raman modes which are strongly affected and decrease with increasing atomic number. The establishment of a facile synthesis strategy allows the application of these Ag-delafossite systems in many disciplines, i.e. in heterogeneous catalysis and as optoelectronic device.
\end{abstract}




\section{Introduction}

Delafossite $\left(\mathrm{CuFeO}_{2}\right)$, first reported in 1873 by $\mathrm{C}$. Friedel, is the name-giving member of a structure type for ternary oxides with the general formula $A B \mathrm{O}_{2 .}{ }^{[1]}$ The compositional diversity of the structure includes monovalent $A$-site cations of the semi-noble or noble metals $\mathrm{Cu}, \mathrm{Ag}, \mathrm{Pd}$ or Pt and various trivalent $B$-site cations from group 13 , transition metals or lanthanides in the range of $0.53<\mathrm{r}_{\text {IV }}{ }^{\text {(III) })<1.03 \AA . ~}{ }^{[2]}$

The report of p-type conductivity and transparency in $\mathrm{CuAlO}_{2}$ thin films by Kawazoe et al. in 1997 demonstrated the technological importance of this compound class. ${ }^{[3]}$ Since then, Ag-delafossites $\left(\mathrm{AgBO}_{2}\right)$ containing group $13(\mathrm{Al}, \mathrm{Ga}, \mathrm{In}) \mathrm{B}$-site cations have been of growing interest due to their optoelectronic properties. ${ }^{[2 b, 2 c, 4]}$ Hence, their application as transparent conductive oxides (TCO), when deposited as thin films ${ }^{[5]}$ or photocatalysts ${ }^{[6]}$ are explored.
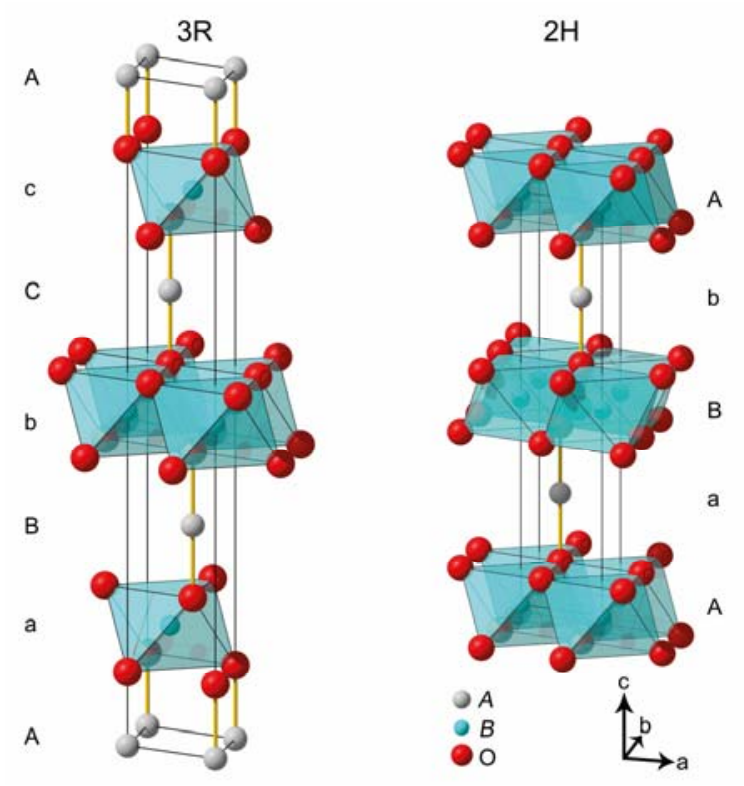

Figure 1: Schematic representation of the $A B \mathrm{O}_{2}$ delafossite crystal structure for the $3 \mathrm{R}$ polytype (left) and $2 \mathrm{H}$ (right) polytype. ${ }^{[7]}$ The sequence of the close-packed $A$-layer and $B \mathrm{O}_{2}$-layer in the direction of the stacking-axis $c$ are given.

The crystal structure consists of close-packed Ag' layers and sheets of slightly distorted edgeshared $B^{\prime \prime \prime} \mathrm{O}_{6}$ octahedra $\left(\mathrm{BO}_{2}\right.$ layer) stacked along the $c$-axis (Figure 1). Linear coordination of $\mathrm{Ag}^{\prime}$ by two oxygen atoms along the $c$-axis leads to the interlinkage of the adjacent $\mathrm{BO}_{2}$ layers. Each oxygen atom is tetrahedrally coordinated by four cations ( $\mathrm{Ag}$ and $3 \mathrm{~B}$ ). Two polytypes of the delafossite structure can form as given in Figure 1. ${ }^{[8]}$ The rhombohedral 3R type (space group $R$ $3 m$, No. 166) originates from the AaBbCc stacking pattern and is experimentally known for all $B$ site ions dealt with in this work. ${ }^{[2 a, 9]}$ Besides, the $\mathrm{AaBb}$ ordered hexagonal $2 \mathrm{H}$ polytype (space group $P 6_{3} / m m c$, No, 194) has been solely obtained for $B$ : Al. ${ }^{[10]}$ Because the reagent $\mathrm{Ag}_{2} \mathrm{O}$ $\left(\Delta \mathrm{G}_{\mathrm{f}}{ }^{0}=-11.2 \mathrm{kJmol}^{-1[11]}\right)$ decomposes in open systems already above $573 \mathrm{~K}^{[12]}$, the preparation of Ag-delafossites is difficult and requires special conditions. In the early 1970 s Shannon et al. introduced different closed-system techniques for their preparation, namely metathetical, oxidizing flux and high temperature hydrothermal methods. ${ }^{[12]}$ However, each method suffered from limitations, such as the formation of highly stable silver halides in case of metathetical reaction 
path ${ }^{[12]}$ or $\mathrm{Ag}_{2} \mathrm{O} / \mathrm{Ag}$ by-phase in the latter cases ${ }^{[2 \mathrm{~b}-\mathrm{d}, 5 \mathrm{a}, 12-13]}$. Even low amounts of $3 \mathrm{R}-\mathrm{AgGaO}_{2}$ could be prepared by solid-state reaction using a diamond anvil cell to generate high pressures $\left(>10^{5}\right.$ bar) and temperatures $(\geq 753 \mathrm{~K})$, as recently reported by Akhtar et al.. ${ }^{[14]}$

Particularly the preparation by hydrothermal synthesis techniques advanced from the early stage of both high-temperature and pressure regimes $\left(773-973 \mathrm{~K}^{[9,12]}\right.$ and up to $20 \cdot 10^{3}$ bar $\left.^{[0]}\right)$, utilizing sealed thin-walled Pt or Au tubes to more practical synthesis conditions today. This includes the use of sealed semipermeable fluoro(ethylene-propylene) (FEP) pouches ${ }^{[15]}$ for the preparation of various Ag-delafossites, as introduced by Poeppelmeier and coworkers. The reaction involves equimolar ratios of the corresponding metal oxides and the mineralizer $\mathrm{NaOH} .3 \mathrm{R}-\mathrm{AgBO} \mathrm{B}_{2}(\mathrm{~B}: \mathrm{Al}$, $\mathrm{Ga}$, In) could be obtained at considerable milder temperatures (448-483 K) and autogenous pressures ( $<20$ bar) conditions and reaction times of several days. ${ }^{[2 \mathrm{~b}-\mathrm{d}, 6 \mathrm{~b}]}$ In addition, Xiong et al. reported the preparation of $3 \mathrm{R}-\mathrm{AgAlO}{ }_{2}$ from the metal nitrates treated under alkaline conditions in a PTFE-lined pressure vessel at $463 \mathrm{~K}$ for multiple days. However, the as-prepared product suffered from pronounced $\mathrm{Ag}_{2} \mathrm{O}$ contamination which must be leached off by a subsequent multistep washing procedure. ${ }^{[16]}$

Any potential application of $3 \mathrm{R}-\mathrm{AgBO}_{2}(\mathrm{~B}: \mathrm{Al}, \mathrm{Ga}, \mathrm{In})$ requires reproducible, scalable and ideally convenient synthetic techniques to obtain products of high purity. We addressed this by developing a time-saving simple hydrothermal synthesis route using common PTFE-lined pressure vessels for $3 \mathrm{R}-\mathrm{AgBO} \mathrm{O}_{2}(\mathrm{~B}: \mathrm{Al}, \mathrm{Ga}, \mathrm{In})$. Further, the scalability of the process was demonstrated by the synthesis of $3 \mathrm{R}-\mathrm{AgAlO}_{2}$. We comparatively studied the structure and bonding situation in these iso-structural compounds experimentally and by means of ab-initio calculations. As a metal oxidic solid-solution, the ternary silver oxides $3 \mathrm{R}-\mathrm{AgBO}_{2}(\mathrm{~B}: \mathrm{Al}, \mathrm{Ga}, \mathrm{In})$ presents a potential precursor for $\mathrm{Ag} / \mathrm{B}_{2} \mathrm{O}_{3}$ based catalysts, which were so far realized by impregnation techniques. Consequently, to explore their potential as catalysts, the thermal reactivity of the Agdelafossites was investigated.

\section{Results and Discussion}

\section{Synthesis of Ag-delafossites}

$3 R-\mathrm{AgAlO}_{2}$

With $\mathrm{Ag}_{2} \mathrm{O}$ and $\alpha-\mathrm{Al}_{2} \mathrm{O}_{3}$ as starting material, the effect of reactant ratio, $\mathrm{NaOH}$ (mineralizer) concentration and reaction time on the hydrothermal preparation of $3 \mathrm{R}-\mathrm{AgAlO}{ }_{2}$ were investigated using standard PTFE-lined pressure vessels. All samples are designated according to the selected $B$-site ion and the parameter under evaluation (i.e. equimolar Al and Ag ratio is named as Al_1eq). An average particle size of $40 \mathrm{~nm}$ for $\alpha-\mathrm{Al}_{2} \mathrm{O}_{3}$, has been selected based on initial pretests (Table S4). The synthesis parameters for the preparation of $3 \mathrm{R}-\mathrm{AgAlO}_{2}$ are listed in Table 1 and the corresponding XRD patterns are presented as close ups in Figure 2 (XRD patterns from $10-60^{\circ}$ are given in Figure $\mathrm{S} 1$ to $\mathrm{S} 3$ ). 
Table 1: Experimental details for the preparation of $3 \mathrm{R}-\mathrm{AgAlO} \mathrm{Al}_{2}$ by using different reactant ratios, mineralizer concentrations or synthesis times. All samples were prepared at a reaction temperature of $483 \mathrm{~K}$ and a fixed batch size of $1.8 \mathrm{~g}$. Data set includes the phase analysis by XRD. Highlighted parameters were varied within a sample series. Optimized conditions shaded (grey).

\begin{tabular}{|c|c|c|c|c|}
\hline \multirow[t]{2}{*}{ Sample } & \multicolumn{3}{|c|}{ Values of parameters } & \multirow[t]{2}{*}{ Phases $^{[b]}$} \\
\hline & $\mathrm{Al}: \mathrm{Ag}^{[\mathrm{a}]}$ & $\mathrm{NaOH}[\mathrm{M}]$ & $\mathrm{t}[\mathrm{h}]$ & \\
\hline Al_1eq & $1: 1$ & 0.9 & 60 & $\underline{3 \mathrm{R}-\mathrm{AgAlO}} 2, \mathrm{Ag}, \mathrm{Ag}_{2} \mathrm{O}, \mathrm{Ag}_{2} \mathrm{CO}_{3}$ \\
\hline Al_2eq & $2: 1$ & 0.9 & 60 & $\underline{3 \mathrm{R}-\mathrm{AgAlO}} 2, \mathrm{Ag}$ \\
\hline Al_3eq & $3: 1$ & 0.9 & 60 & $\underline{3 \mathrm{R}-\mathrm{AgAlO}} 2, \mathrm{Ag}, \mathrm{y}-\mathrm{AlOOH}$ \\
\hline Al_0.1M & $2: 1$ & 0.1 & 60 & $\underline{3 \mathrm{R}-\mathrm{AgAlO}} 2, \mathrm{Ag}, \alpha-\mathrm{Al}_{2} \mathrm{O}_{3}, \mathrm{\gamma}-\mathrm{AlOOH}$ \\
\hline Al_0.9M & $2: 1$ & 0.9 & 60 & $\underline{3 \mathrm{R}-\mathrm{AgAlO}} 2, \mathrm{Ag}$ \\
\hline Al_1.5M & $2: 1$ & 1.5 & 60 & $\underline{3 \mathrm{R}-\mathrm{AgAlO}} 2, \mathrm{Ag}$ \\
\hline Al_60h & $2: 1$ & 0.9 & 60 & $\underline{3 \mathrm{R}-\mathrm{AgAlO}} 2, \mathrm{Ag}$ \\
\hline Al_45h & $2: 1$ & 0.9 & 45 & $\underline{3 \mathrm{R}-\mathrm{AgAlO}} 2, \mathrm{Ag}$ \\
\hline Al_30h[c] & $2: 1$ & 0.9 & 30 & $\underline{3 \mathrm{R}-\mathrm{AgAlO}} 2$ \\
\hline
\end{tabular}

[a] Molar ratio of elements. [b] The underlined phases are the majority phases (XRD). [c] Graphical representations of the Rietveld refined XRD data given in Figure $7 a$.

The use of an equimolar ratio of $\mathrm{Al}$ and $\mathrm{Ag}$, as selected in the FEP Teflon pouch method ${ }^{[2 \mathrm{~b}, 2 \mathrm{c}, 6 \mathrm{~b}]}$ leads to the formation of $3 \mathrm{R}-\mathrm{AgAlO}$ and additional by-phases of $\mathrm{Ag}_{2} \mathrm{O}, \mathrm{Ag}_{2} \mathrm{CO}_{3}$ and elemental $\mathrm{Ag}$ (Figure 2a). As the molar Al: Ag ratio is raised to 2, Ag remains the sole secondary phase (Figure $2 b)$. A further increase of the Al content to 3 equivalents is not beneficial, as the presence of an additional $\mathrm{Y}$-AIOOH phase is observed. After-reaction analysis of the colorless liquors by ICP-OES noticeable Al amounts were detected in all cases (Table S5).

Hydrothermal synthesis can be regarded as a special type of chemical transport reaction. ${ }^{[17]}$ As such, the dissolution of the educts (hydrolysis of the reactants) is crucial. To enhance the solubility mineralizers ${ }^{[18]}$ such as $\mathrm{NaOH}$ are commonly used in the hydrothermal preparation of Agdelafossites. ${ }^{[2 c, 12,19]}$ The effect of varying the $\mathrm{NaOH}$ concentration between $0.1-1.5 \mathrm{M}$ on the obtained phase compositions is presented as XRD patterns in Figure $2 \mathrm{~b}$. Low mineralizer concentration $(0.1 \mathrm{M})$ leads to the presence of undissolved $\alpha-\mathrm{Al}_{2} \mathrm{O}_{3}$ and the occurrence of $\mathrm{y}-\mathrm{AlOOH}$ besides an $\mathrm{Ag}$ trace impurity and the crystalline $3 \mathrm{R}-\mathrm{AgAlO}_{2}$ main phase. The presence of the aluminous by-product $\mathrm{y}-\mathrm{AlOOH}$ is explained by the linkage of the solids $\mathrm{Al}_{2} \mathrm{O}_{3}, \mathrm{AlOOH}$ and $\mathrm{Al}(\mathrm{OH})_{3}$ polymorphs as part of the hydration reactions ${ }^{[20]}$ :

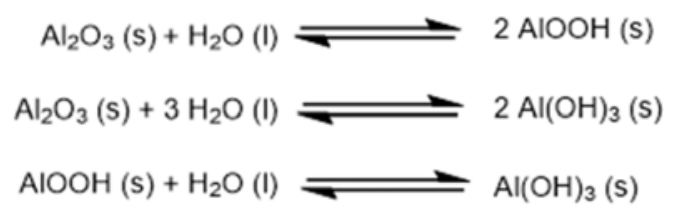


In aqueous solutions, the two polymorphs of $\mathrm{Al}_{2} \mathrm{O}_{3}$ are not stable below $653 \mathrm{~K}$ (Equation $1+2$ ), while for $\mathrm{Al}(\mathrm{OH})_{3}$ they are not stable above $353 \mathrm{~K}$ (Equation $2+3$ ). They transform into the kinetically favored $y$-modification of $\mathrm{AIOOH}(\mathrm{Eq} .1+3)^{[21]}$, which is the solubility-controlling phase under hydrothermal conditions. ${ }^{[22]}$ Its solubility has been extensively studied and increases at elevated temperature and strong alkaline media. ${ }^{[22-23]}$ Hence, no aluminous secondary phases were present after the $\mathrm{NaOH}$ concentration was adjusted to $\geq 0.9 \mathrm{M}$, but almost exclusively $3 \mathrm{R}$ $\mathrm{AgAlO}_{2}$ (Figure 2b, Al_0.9M and Al_1.5M). Besides, the as-prepared samples still featured trace impurities of $\mathrm{Ag}(<1 \mathrm{wt}$. \%). Its presence has already been frequently reported in the context of Ag-delafossite synthesis. ${ }^{[2 b, 24]}$ and identified as impurity on the $\mathrm{Ag}_{2} \mathrm{O}$ educt. ${ }^{[2 \mathrm{~d}]}$ However, in the present work this obstacle was not observed after a significant decrease of the hydrothermal reaction time from the common $60 \mathrm{~h}$ to $30 \mathrm{~h}$. As evidenced by the given XRD data in Figure 2c phase pure $3 \mathrm{R}-\mathrm{AgAlO}_{2}$ was obtained (see also Table 1).

A possible explanation for the presence of the Ag by-phase might be the limited stability of the delafossite product phase under the hydrothermal reaction conditions. To clarify this issue, the stability of the phase-pure $3 \mathrm{R}-\mathrm{AgAlO}_{2}$ and the educt $\mathrm{Ag}_{2} \mathrm{O}$ were investigated in a model experiment by exposing them to identical hydrothermal reaction conditions. The corresponding $\mathrm{XRD}$ patterns of the treated samples are presented as close ups in Figure $3 \mathrm{a}$. In the case of the ex_Ag $2 \mathrm{O}$ sample the diffraction pattern still coincides solely with the pure $\mathrm{Ag}_{2} \mathrm{O}$ (PDF2 card no 411104). After the 60-hour hydrothermal treatment at $483 \mathrm{~K} 3 \mathrm{R}-\mathrm{AgAlO}_{2}$ (ex_AgAlO $\mathrm{A}_{2}$, Figure 3a) decomposed to $\mathrm{Ag}_{2} \mathrm{O}$ and elemental $\mathrm{Ag}$. The latter is evidenced by the presence of the $\mathrm{Ag} 111$ reflection at $38.1^{\circ} 2 \theta$ (diffraction pattern from $25-75^{\circ} 2 \theta$ in Figure S4). This observation further corroborated the metastability of the Ag-delafossite phase under the given synthesis conditions.

In order to further investigate the influence on the actual synthesis of $3 \mathrm{R}-\mathrm{AgAIO}$, the hydrothermal synthesis time was systematically varied in the range of $3-60 \mathrm{~h}$ in the subsequent experiments. To fasten the dissolution of the educts, increase their liquid-phase transport and intensify the heat transfer the reaction mixture was stirred. For all samples, quantitative phase analysis of the multicomponent mixtures using X-ray powder diffraction data has been performed using the Rietveld method. The evolution of the approximate phase amounts as a function of the synthesis time are presented in Figure $3 \mathrm{~b}$. The corresponding diffraction patterns are given in Figure S5. Already after $3 \mathrm{~h}$ the presence of about $10 \mathrm{wt} . \% 3 \mathrm{R}-\mathrm{AgAlO}{ }_{2}$ is detected. After a further increase to $10 \mathrm{~h}$ its proportion has increased to $95 \mathrm{wt}$. \%. The contribution of the $\alpha-\mathrm{Al}_{2} \mathrm{O}_{3}$ educt drastically decreased, respectively both crystalline $\mathrm{Ag}_{2} \mathrm{O}$ and $\mathrm{Ag}_{2} \mathrm{CO}_{3}$ are no longer detectable. As highlighted, high purity $3 \mathrm{R}-\mathrm{AgAlO} \mathrm{Al}_{2}$ could be obtained in the time frame of $12-19 \mathrm{~h}$. An additional increase of the hydrothermal synthesis time $(40-60 \mathrm{~h})$ is not beneficial. This is due to the rising contribution of a Ag by-phase leading to a contamination of about $12 \mathrm{wt}$. \% Ag after $60 \mathrm{~h}$. 

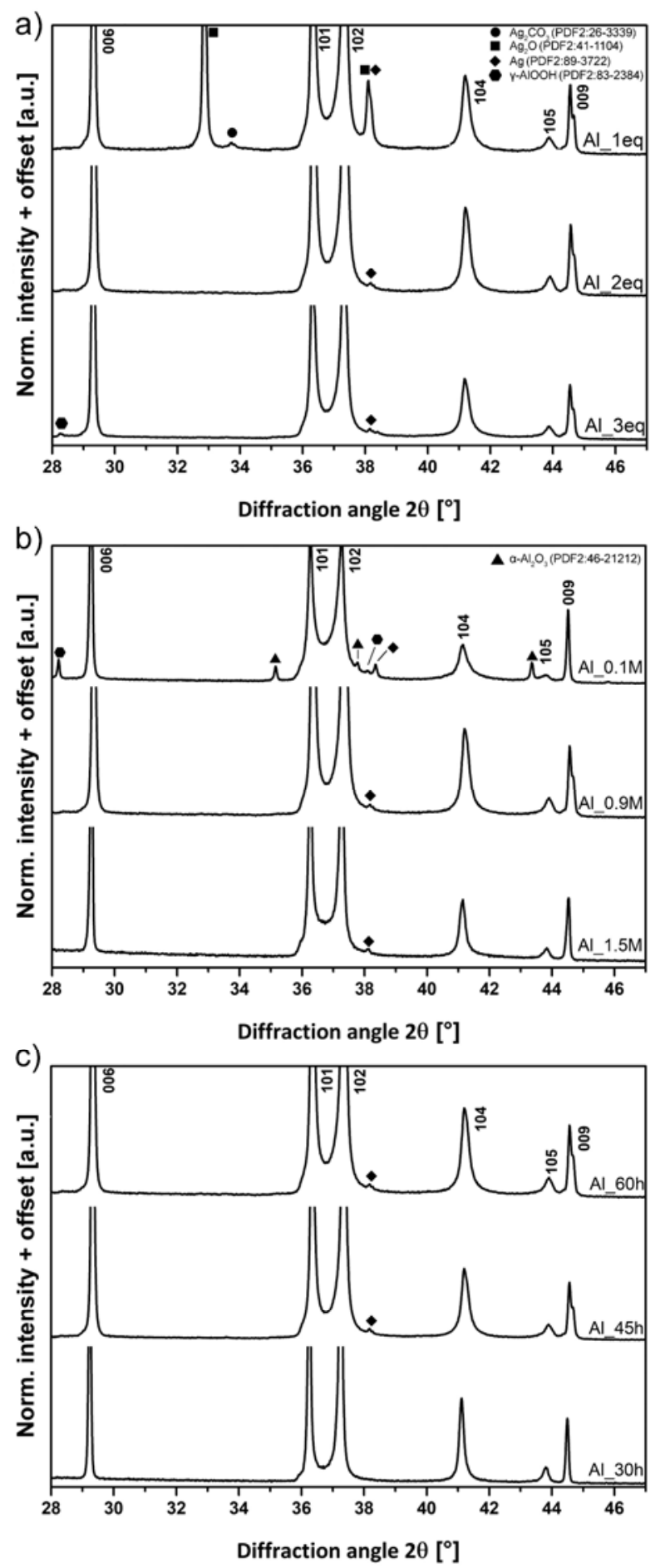

Figure 2: XRD patterns of as-synthesized samples obtained after variation of educt ratio (a), $\mathrm{NaOH}$ content (b) and reaction time (c). Indices are given for the crystalline main phase 3R-AgAIO2. The corresponding overview XRD patterns from $10-60^{\circ} 2 \theta$ are given in Figure S1 - S3. 

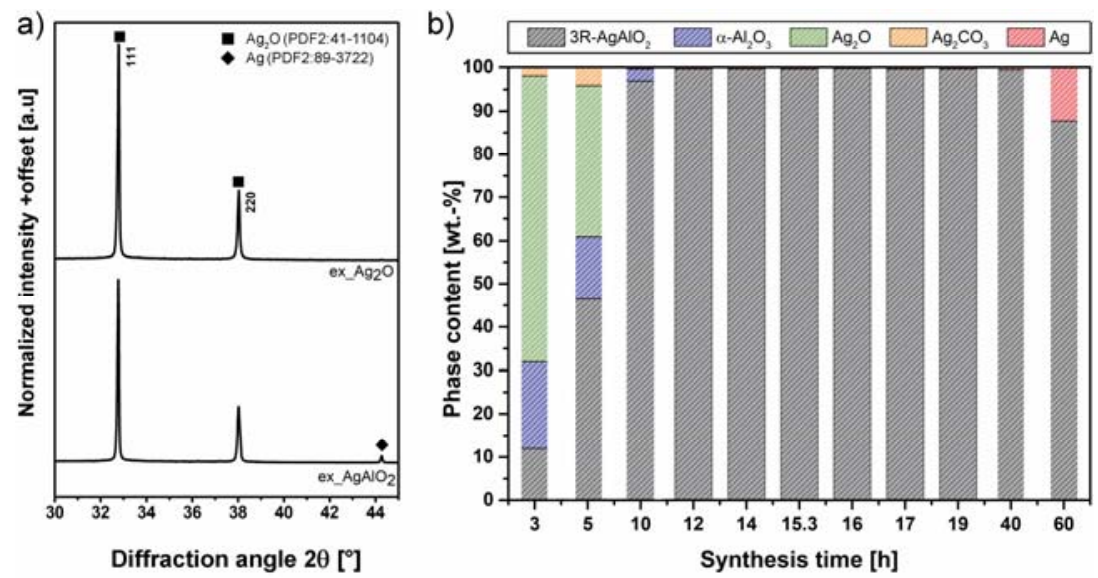

Figure 3: $\mathrm{XRD}$ patterns of $\mathrm{Ag}_{2} \mathrm{O}$ and $3 \mathrm{R}-\mathrm{AgAlO}_{2}$ after treatment in $0.9 \mathrm{M} \mathrm{NaOH}$ at $483 \mathrm{~K}$ for $60 \mathrm{~h}$ (a) and the evolution of the phase composition as a function of the applied hydrothermal synthesis time (b). Phase contents derived by quantitative XRD analysis. Optimized synthesis time frame highlighted (12-19 h).

The volcano-shaped time dependent evolution of the $3 \mathrm{R}-\mathrm{AgAlO}_{2}$ phase contribution (Figure $3 \mathrm{~b}$ ) evidently indicates the presence of competing processes taking place during the hydrothermal treatment. The sketch in Figure 4 visualize a proposed reaction scheme, whereby a detailed kinetic analysis of these processes is beyond the scope of this work. However, it is expected that this includes at least the Ag-delafossite phase formation and its concurrent decomposition attributed to its apparently metastable nature (see sketch in Figure 4). Hence, phase-pure $3 \mathrm{R}-\mathrm{AgAlO} \mathrm{A}_{2}$ may by all means solely be obtained as the kinetically favored product. The solid

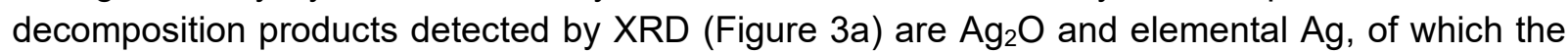
former apparently readily reacts again to the $\mathrm{Ag}$-delafossite phase. The major soluble species of the amphoteric $\mathrm{Ag}_{2} \mathrm{O}^{[25]}$ is reportedly $\left[\mathrm{Ag}(\mathrm{OH})_{2}\right]^{-[26]}$. In contrast, the elemental Ag features a lower solubility in alkaline media[26] and presumably accumulates in the reaction mixture over time and is detected in the as-prepared product by XRD analysis (60 h in Figure $2 \mathrm{c}$ or Figure $3 \mathrm{~b}$ ). By agitation these processes are accelerated, however this also makes shorter reaction times feasible. In a first scale-up, high-purity product in the double-digit gram range was obtained (Figure S6).

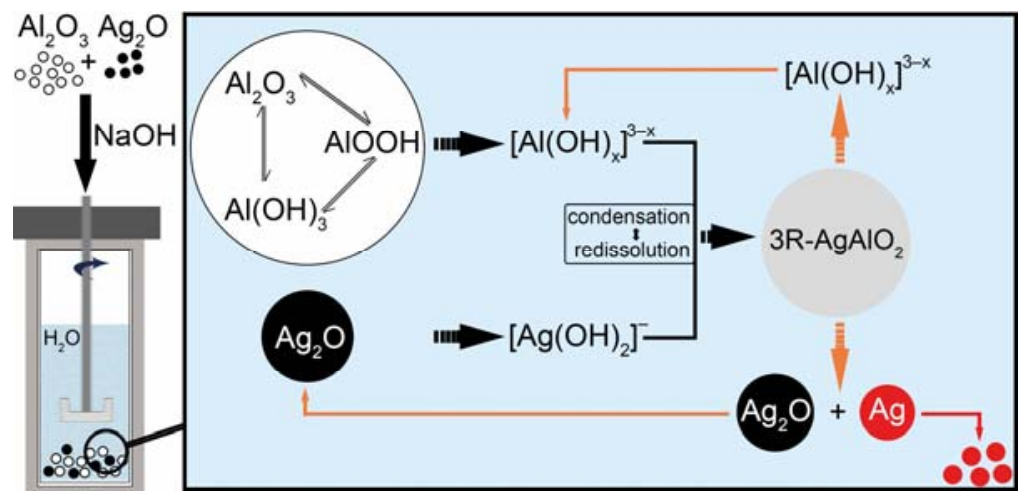

Figure 4: Sketch of the proposed reaction scheme for the $3 \mathrm{R}-\mathrm{AgAlO}_{2}$ phase formation and decomposition (orange arrows) via hydrothermal treatment. Of the specified compounds, only the solid phases are detected in the course of this work (XRD). 


\section{$3 R-\mathrm{AgGaO}_{2}$}

For the Ag-delafossite comprising the heavier group 13 element $\mathrm{Ga}$ as $B$-site ion, the optimized synthesis of $3 \mathrm{R}-\mathrm{AgAlO}{ }_{2}$ served as the starting point. The aqueous chemistry of Gall' and All"I share some resemblance, including the amphoteric behavior of their oxides. ${ }^{[18]} 3 \mathrm{R}-\mathrm{AgGaO}_{2}$ was prepared by the hydrothermal reaction of the respective metal oxides in $0.9 \mathrm{M} \mathrm{NaOH}$ solution at $483 \mathrm{~K}$. In addition, the effect of reactant ratio and the synthesis time have been examined to obtain a high-purity product. The experimental details are summarized in Table 2 and the corresponding powder X-ray diffraction patterns are presented in Figure 5 (overview patterns in Figure S7 and S8).

The use of stochiometric amounts of the amphoteric Ga-sesquioxide $\left(\mathrm{Ga}_{2} \mathrm{O}_{3}\right)$ and $\mathrm{Ag}_{2} \mathrm{O}$ lead to the formation of $3 \mathrm{R}-\mathrm{AgGaO}$ and additional minor contributions from Ag-containing byproducts namely $\mathrm{Ag}_{2} \mathrm{O}, \mathrm{Ag}_{2} \mathrm{CO}_{3}$ and $\mathrm{Ag}$ (Figure $4 \mathrm{a}$ ). Adjusting the $\mathrm{Ga}$ content to a value $\geq 2$ eq., $3 \mathrm{R}-\mathrm{AgGaO}_{2}$ formed almost exclusively.

Table 2 Experimental details of the prepared $3 \mathrm{R}-\mathrm{AgGaO}_{2}$ samples by varying reactant ratios or reaction times. Batch size $(1.8 \mathrm{~g}), \mathrm{NaOH}$ concentration $(0.9 \mathrm{M})$ and reaction temperature $(483 \mathrm{~K})$ fixed for all experiments. Data set includes the phase composition (XRD). Final set of optimized parameters shaded (grey).

\begin{tabular}{|c|c|c|c|}
\hline \multirow[t]{2}{*}{ Sample } & \multicolumn{2}{|c|}{ Values of parameters } & \multirow[t]{2}{*}{ Phases $^{[b]}$} \\
\hline & $\mathrm{Ga}: \mathrm{Ag}^{[\mathrm{a}]}$ & $\mathrm{t}[\mathrm{h}]$ & \\
\hline Ga_1eq & $1: 1$ & 30 & $\underline{3 \mathrm{R}-\mathrm{AgGaO}} 2, \mathrm{Ag}, \mathrm{Ag}_{2} \mathrm{O}, \mathrm{Ag}_{2} \mathrm{CO}_{3}$ \\
\hline Ga_2eq & $2: 1$ & 30 & $\underline{3 \mathrm{R}-\mathrm{AgGaO}_{2}}, \mathrm{Ag}$ \\
\hline Ga_3eq & $3: 1$ & 30 & $\underline{3 \mathrm{R}-\mathrm{AgGaO}_{2}}, \mathrm{Ag}$ \\
\hline Ga_30h & $2: 1$ & 30 & $\underline{3 \mathrm{R}-\mathrm{AgGaO}}, \mathrm{Ag}$ \\
\hline Ga_20h & $2: 1$ & 20 & $\underline{3 \mathrm{R}-\mathrm{AgGaO}_{2}}, \mathrm{Ag}$ \\
\hline Ga_10h[c] & $2: 1$ & 10 & $\underline{3 \mathrm{R}-\mathrm{AgGaO}} 2,(\mathrm{Ag})$ \\
\hline
\end{tabular}

[a] Molar ratio of elements. [b] The underlined phases are the majority phases (XRD). [c] Graphical representations of the Rietveld refined XRD data given in Figure $7 \mathrm{~b}$.

Besides, the as-prepared sample contained minor elemental Ag contamination ( $<1 \mathrm{wt}$. \%). Overall, the results are similar to the $B$-site ion $\mathrm{Al}$ (see Figure 2a). However, here no crystalline $B$-containing phase was observed after an additional increase of the reactant ratio (Ga_3eq, Figure 5a). This might be correlated to the less pronounced amphoteric character of $\mathrm{Ga}$ oxides, which comprise some acidic properties. This goes in line with the reported higher solubility of GallI (compared to $\left.\mathrm{Al}{ }^{\prime \prime \prime}\right)$ in alkaline media at elevated temperature $(473 \mathrm{~K}){ }^{[27]}$

As in the Al-case, the presence of the Ag by-phase was further addressed by a decrease in the reaction time. By lowering the hydrothermal synthesis time from $30 \mathrm{~h}$ to $10 \mathrm{~h}$, the contribution of the Ag by-phase could be largely reduced, close to the detection limit ( $\mathrm{Ga}$ _10h, Figure 5b.). This observation was tentatively interpreted as being related to the metastability of the isomorphous 
Ag-delafossite product phase. As a side effect, the total synthesis time requirement was successfully cut by $90 \%$, when compared to the established FEP pouch method. ${ }^{[4 b]}$
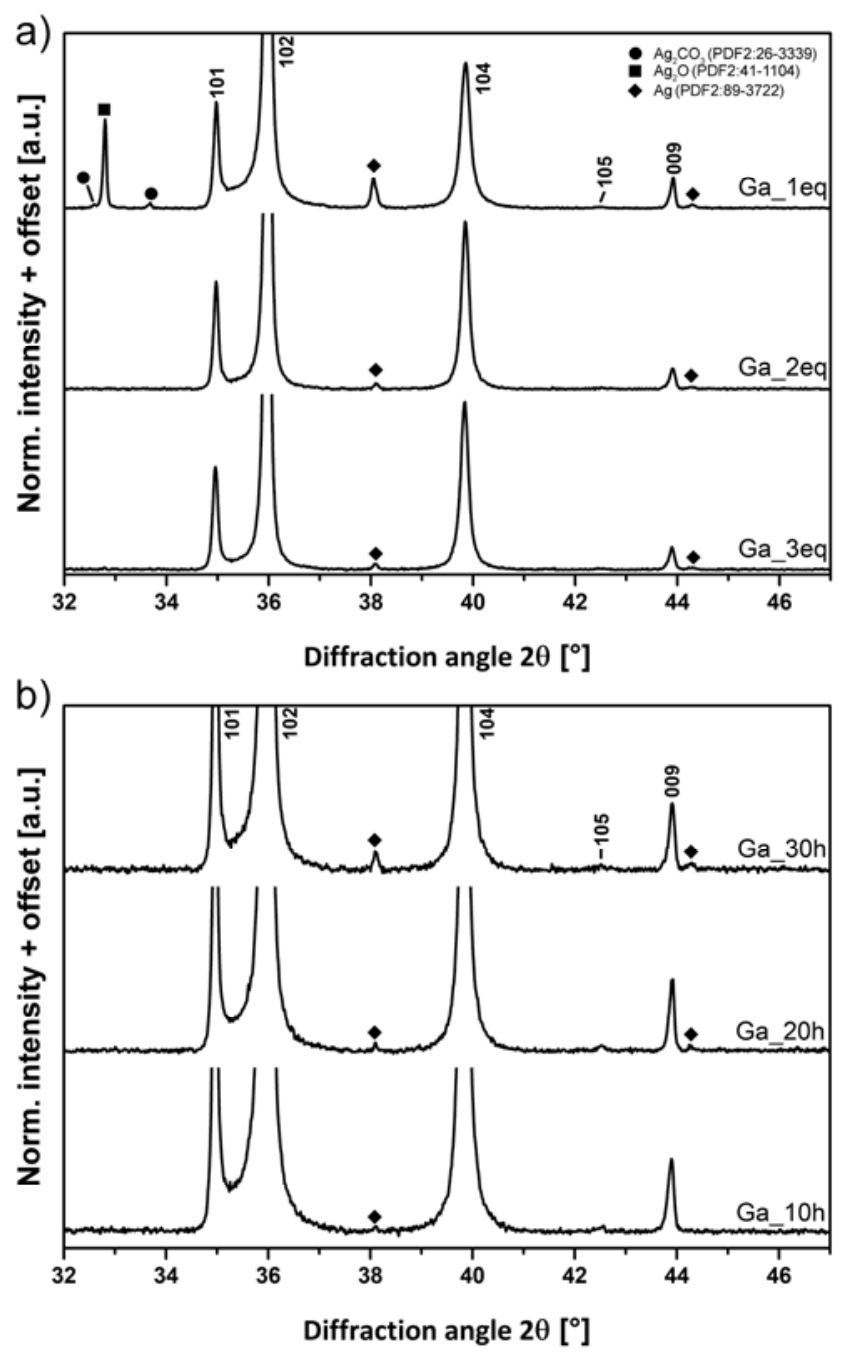

Figure 5: XRD patterns of as-synthesized samples obtained after variation of educt ratio (a) and reaction time (b). Indices are given for the crystalline main phase $3 \mathrm{R}-\mathrm{AgGaO}_{2}$. The corresponding overview diffraction patterns from $10-$ $60^{\circ} 2 \theta$ are given in Figure S7 and S8.

\section{$3 R-\mathrm{AgInO}_{2}$}

The experimental parameters for the hydrothermal synthesis of the Ag-delafossite comprising the group $13 B$-site ion In, are given in Table 3 . Within the investigated educt ratios, the formation of $3 \mathrm{R}-\mathrm{AgInO} \mathrm{O}_{2}$ as the crystalline mainphase could be observed (Figure 6). However, the as-prepared samples suffered from the presence of In-containing secondary phases, namely the sesquioxide educt $\left(\ln _{2} \mathrm{O}_{3}\right)$ and $\operatorname{In}(\mathrm{OH})_{3}$. This might be attributed to the fairly limited solubility of $\ln$ oxides in alkaline media (in contrast to amphoteric $\mathrm{Al}^{\prime \prime \prime}$ and $\left.\mathrm{Ga}^{1 \mathrm{II}}\right) \cdot{ }^{\left[{ }^{[2]}\right.}$ Hence, a reduction of the hydrothermal synthesis time did not seem reasonable, as it was expected to lead to a rising contribution of the In-containing by-phases in the final product. Therefore, the reactant ratio was fixed to one and the 
batch size was decreased $(1.4 \mathrm{~g})$. As a result, no $\ln (\mathrm{OH})_{3}$ contamination could be detected in the product anymore, but a trace impurity of elemental Ag (Figure 7c). As for the lighter group $13 \mathrm{~B}$ site ions $\mathrm{Al}$ and $\mathrm{Ga}$, its presence is interpreted as an indication for the metastability of the Agdelafossite product phase.

Table 3 Experimental details of the prepared $3 \mathrm{R}-\mathrm{AglnO}_{2}$ samples by varying reactant ratios and sample mass. For all experiments the same $\mathrm{NaOH}$ concentration $(0.9 \mathrm{M})$, reaction temperature $(483 \mathrm{~K})$ and reaction time $(30 \mathrm{~h})$ were used. Data set includes the phase composition (XRD). Final set of optimized parameters shaded (grey).

\begin{tabular}{|c|c|c|c|}
\hline \multirow[t]{2}{*}{ Sample } & \multicolumn{2}{|c|}{ Values of parameters } & \multirow[t]{2}{*}{ Phases $^{[b]}$} \\
\hline & In : Ag ${ }^{[a]}$ & Batch size [g] & \\
\hline In_1eq & $1: 1$ & 1.8 & $\underline{3 \mathrm{R}-\mathrm{Ag} \ln \mathrm{O}_{2}}, \ln (\mathrm{OH})_{3}, \ln _{2} \mathrm{O}_{3}$ \\
\hline In_1.5eq & $1.5: 1.0$ & 1.8 & $\underline{3 \mathrm{R}-\mathrm{Ag} \ln \mathrm{O}_{2}}, \ln (\mathrm{OH})_{3}, \ln _{2} \mathrm{O}_{3}$ \\
\hline In_2eq & $2: 1$ & 1.8 & $\underline{3 \mathrm{R}-\mathrm{Ag} \ln \mathrm{O}_{2}}, \ln (\mathrm{OH})_{3}, \ln _{2} \mathrm{O}_{3}$ \\
\hline In_1.4g[c] & $1: 1$ & 1.4 & $\underline{3 \mathrm{R}-\mathrm{Ag} \ln \mathrm{O}_{2}}, \mathrm{In}_{2} \mathrm{O}_{3}, \mathrm{Ag}$ \\
\hline
\end{tabular}

[a] Molar ratio of elements. [b] The underlined phases are the majority phases (XRD). [c] Graphical representations of the Rietveld refined XRD data given in Figure $7 \mathrm{c}$.

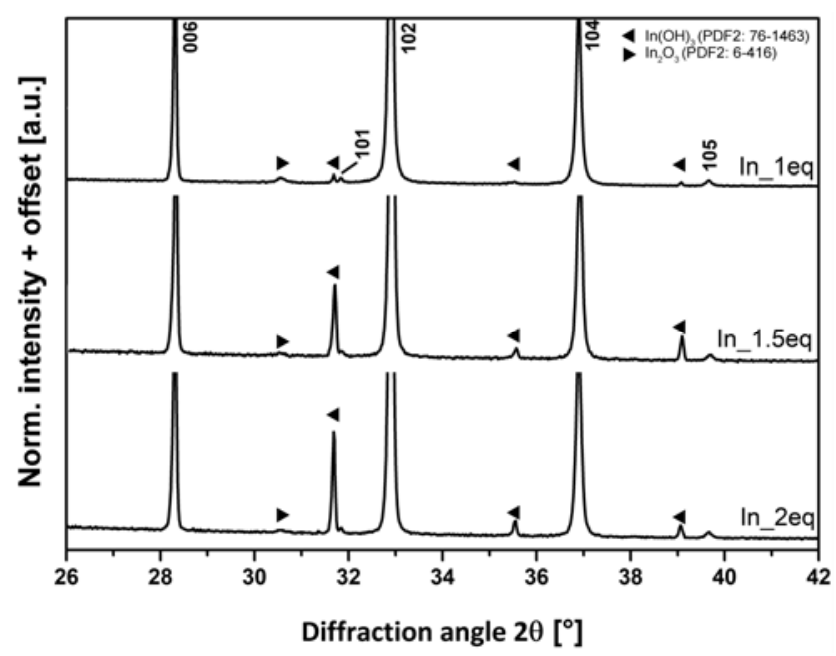

Figure 6: XRD patterns of as-synthesized samples obtained after variation of educt ratio. Indices are given for the crystalline main phase $3 \mathrm{R}-\mathrm{Ag} \mathrm{InO}_{2}$. The corresponding overview diffractograms from $10-60^{\circ} 2 \theta$ are given in Figure S9.

The three isostructural ternary oxides $3 \mathrm{R} \mathrm{AgBO}_{2}(\mathrm{~B}: \mathrm{Al}, \mathrm{Ga}, \mathrm{In})$ obtained by the optimized synthesis protocols (see shaded rows in Table 1-3) were further comparatively studied with respect to their structure and bonding situation. 


\section{Structural properties of $3 \mathrm{R}-\mathrm{AgBO} \mathrm{O}_{2}$}

Table 4: Overview of selected $3 \mathrm{R}-\mathrm{AgBO}_{2}(\mathrm{~B}: \mathrm{Al}, \mathrm{Ga}, \mathrm{In})$ samples including their metal ratios (XRF, ICP-OES), specific surface areas determined by $\mathrm{N}_{2}$-physisorption $\left(S A_{B E T}\right.$ ), band gap energies $\left(E_{\text {gap }}\right)$, conductivity, Raman active modes and decomposition temperatures ( $T_{\text {decomp. }}$. STA-EGA) as well as mass losses due to decomposition (TG). For comparison, the calculated values are given in brackets. In the case of the $E_{\text {gap }}$ the calculated values using LDA, PBE and SCAN are given.

\begin{tabular}{|c|c|c|c|c|c|c|c|c|c|c|}
\hline \multirow[t]{2}{*}{ Sample } & \multicolumn{2}{|c|}{ Metal ratio $[\mathrm{Ag}] /[\mathrm{B}]$} & \multirow{2}{*}{$\begin{array}{l}\text { SA } A_{\text {BET }} \\
{\left[\mathrm{m}^{2} \mathrm{~g}^{-1}\right]}\end{array}$} & \multirow{2}{*}{$\begin{array}{l}E_{\text {gap }} \\
{[\mathrm{eV}]}\end{array}$} & \multicolumn{2}{|c|}{ Conductivity $\left[\mathrm{mScm}^{-1}\right]$} & \multicolumn{2}{|c|}{ Raman modes $\left[\mathrm{cm}^{-1}\right]$} & \multirow{2}{*}{$\begin{array}{r}T_{\text {decomp. }} \\
{[\mathrm{K}]}\end{array}$} & \multirow{2}{*}{$\begin{array}{l}\text { Mass loss } \\
\left.[\mathrm{wt} \%]^{[b]}\right]\end{array}$} \\
\hline & EDX & ICP-OES & & & $303 \mathrm{~K}$ & $473 \mathrm{~K}$ & $E_{g}$ & $A_{1 g}$ & & \\
\hline $3 \mathrm{R}-\mathrm{AgAlO}_{2}$ & $1.07 \pm 0.06$ & -[a] & 1.5 & $3.2(1.5 ; 1.3 ; 2.1)$ & 0,05 & 0,22 & $\begin{array}{l}406 \\
(411)\end{array}$ & $711(714)$ & 1075 & $4.5(4.8)$ \\
\hline $3 \mathrm{R}-\mathrm{AgGaO}_{2}$ & $1.08 \pm 0.03$ & 1.06 & 2.1 & $2.5(0.5 ; 0.6 ; 1.0)$ & 0,19 & 0,37 & $\begin{array}{l}378 \\
(302)\end{array}$ & $674(652)$ & 960 & $3.8(3.8)$ \\
\hline $3 \mathrm{R}-\mathrm{AgInO}{ }_{2}$ & $0.98 \pm 0.15$ & 1.04 & 1.8 & $2.1(0.2 ; 0.2 ; .0 .7)$ & 1,1 & 2,7 & $\begin{array}{l}342 \\
(344)\end{array}$ & $614(618)$ & 900 & $3.1(3.1)$ \\
\hline
\end{tabular}

[a]: No data given, as only partial dissolution of the compound. [b]: Average value of three measurements.

The obtained ternary oxides of the general formula $\mathrm{AgBO}_{2}(\mathrm{~B}: \mathrm{Al}, \mathrm{Ga}, \mathrm{In})$ all crystallize in the delafossite structure. As such, the effect of the $B$-site cation on the structural parameters and the nature of the chemical bonding were investigated. In the delafossite structure nominally $A g^{\prime}(A-$ site) and the group 13 cations Al'", Gall' or In $^{\text {III }}$ (B-site) are present. The anisotropic delafossite structure features single $\mathrm{BO}_{2}$ layers of close-packed $\mathrm{BO}_{6}$ octahedra stacked along the $c$-axis and linked to one another by linear coordination of Ag with two oxygen atoms. For oxygen a tetrahedral coordination results with one $\mathrm{Ag}$ and three $B$-site cations (see Figure 1). All atoms are located on special positions. The crystal structure is described by three variables, the lattice parameters a and $c$ and the $z$-position of the oxygen atom. $\cdot^{[9]}$ Rietveld refinement of these parameters started from the experimentally available single-crystal structure data of $3 R-A g l n O_{2}$ (ICSD entry 202429) $)^{[9]}$, which also served as a starting point for both remaining isostructural Agdelafossites with $\mathrm{B}$ : $\mathrm{Al}, \mathrm{Ga}$.

Rietveld refinement of the XRD patterns confirms phase-purity for the $3 \mathrm{R}-\mathrm{AgAlO} \mathrm{O}_{2}$ sample (Al_30h, Figure $7 \mathrm{a})$. In case of $3 \mathrm{R}-\mathrm{AgGaO}$ ( $\mathrm{Ga} \_10 \mathrm{~h}$ ), a very small peak which corresponds to the $\mathrm{Ag}(111)$ diffraction, is present at $2 \theta \approx 38.1^{\circ}$ (Figure $7 \mathrm{~b}$, inset). The diffraction pattern of $3 \mathrm{R}-\mathrm{AgInO}_{2}\left(\mathrm{In} \_1.4 \mathrm{~g}\right)$ shows the contribution of an additional $\ln _{2} \mathrm{O}_{3}$ (ICSD entry 190344) trace impurity (Figure 6c, inset). While the presence of these additional phases is clearly detectable by PXRD, a reliable quantitative analysis of such traces, which can be estimated to be well below $1 \mathrm{wt}$. \%, is beyond the possibilities of our Rietveld analysis. This is in excellent agreement with the determined cationic content of the samples close to stoichiometry (Table 4). To simplify matters, in the following all samples are named after their respective delafossite phase (i.e. Al_30h as 3R-AgAlO 2 ). 

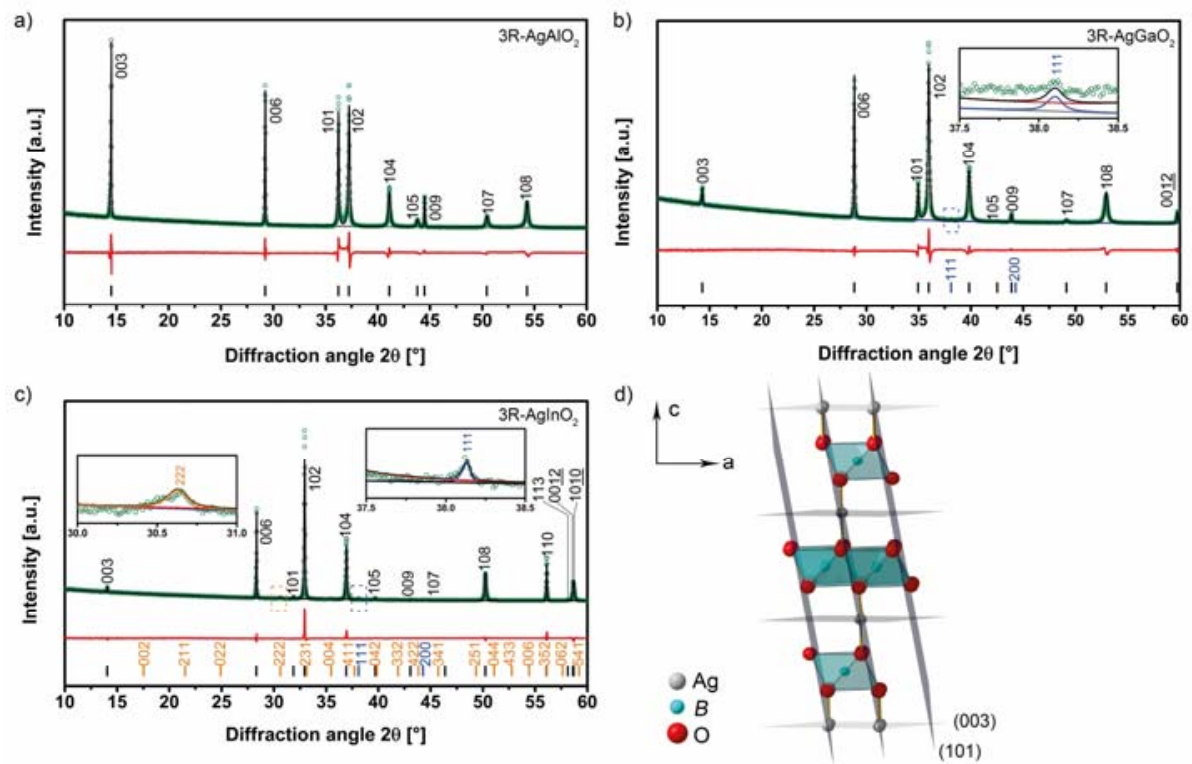

Figure 7: Graphical representations of the Rietveld refined Ag-delafossite powder XRD data (a-c) and delafossite unit cell of 3R polytype with (003) and (101) viewed along $b$-axis (d). Experimental pattern (green circles), calculated data (black line), separate phase contributions of delafossite phase (red line), Ag (blue line) and $\ln _{2} \mathrm{O}_{3}$ (orange line), background (grey line), difference curve (red curve) and peak positions (ticks) are given. Insets in b) and c) show contribution of $\mathrm{Ag}$ (blue ticks) and $\ln _{2} \mathrm{O}_{3}$ (orange ticks) to the diffraction patterns.

The observed X-ray diffraction patterns reflect the anisotropy of the delafossite crystal structure. All samples exhibit a varying degree of anisotropic peak broadening, with sharper interlayer 001 and intralayer $h k 0$ reflections and broader mixed $h k l$ reflections. The effect is strongest for $3 R-$ $\mathrm{AgAlO}_{2}$ and least pronounced in $3 \mathrm{R}-\mathrm{AgInO}$. The same trend is observed for the asymmetry of the bases of the 101 and 102 reflections, which leaves a visible signature in the residual of the Rietveld fits shown in Figure 7. We suspect that these effects are caused by $2 \mathrm{H}$-type stacking faults within the $3 R$ polytype matrix, which would leave the coherency of diffraction and homogeneity of $d$ spacings mostly undisturbed along the stacking axis $c$ and within the $a, b$ plane (Figure $7 d$ ), respectively, while affecting mainly the diagonal directions. This idea is supported by the fact that the synthesis of the pure $2 \mathrm{H}$ phase has been reported only for the Al compound ${ }^{[10]}$. Furthermore, both polytypes of the Ag-delafossite $\mathrm{AgAlO}_{2}, 2 \mathrm{H}$ and $3 \mathrm{R}$ have about the same total energies ${ }^{[49]}$. We assume that the $2 \mathrm{H}$ variant becomes less favorable compared to the $3 \mathrm{R}$ structure for the heavier $B$ cations, thus resulting in a lower faulting probability.

The layered structure was further investigated by TEM analysis. High-resolution STEM images with Z-contrast visualize the layered delafossite structure of $3 \mathrm{R}-\mathrm{AgBO} \mathrm{O}_{2}(\mathrm{~B}$. $\mathrm{Al}, \mathrm{Ga}, \mathrm{In})$, as presented in Figure 8a-c. With higher atomic number of the group $13 B$-site cation, the measured interplanar distances of $d(003)$ planes (spacing of two adjacent Ag layers along the $c$-axis, Figure 7d) becomes larger. The measured values are in good agreement with the XRD data (B; Al: $6.1 \AA, G a: 6.2 \AA$, In: $6.3 \AA$ ). Morphological analysis of the samples was performed by SEM. The SEM micrographs are given in Figure 8d-f. The presence of partially intergrown hexagonal shaped platelets in the micrometer range is observed for all samples. Besides, the occurrence of holes in a minor fraction of the plates leading to a doughnut-like shape was solely found for 3R$\mathrm{AgAlO}_{2}$ featuring edge lengths of up to $2.5 \mu \mathrm{m}$ and a maximum thickness of $0.5 \mu \mathrm{m}$. Textural properties of the faceted particles drastically varied from smooth to rough. Overall, the $3 \mathrm{R}-\mathrm{AgGaO}$ 
sample consists of smaller and thicker platelets (up to $1 \mu \mathrm{m}$ edge length) and less well-defined sub $\mu \mathrm{m}$-sized particles. Even thicker platelets $(0.8 \mu \mathrm{m})$ are obtained when the heavier group 13 element In is present as the $B$-site cation as given in $3 \mathrm{R}$-AglnO 2 . The specific $\mathrm{BET}$ surface area varies at a low level around $2 \mathrm{~m}^{2} \mathrm{~g}^{-1}$ for all samples (Table 4). phase.
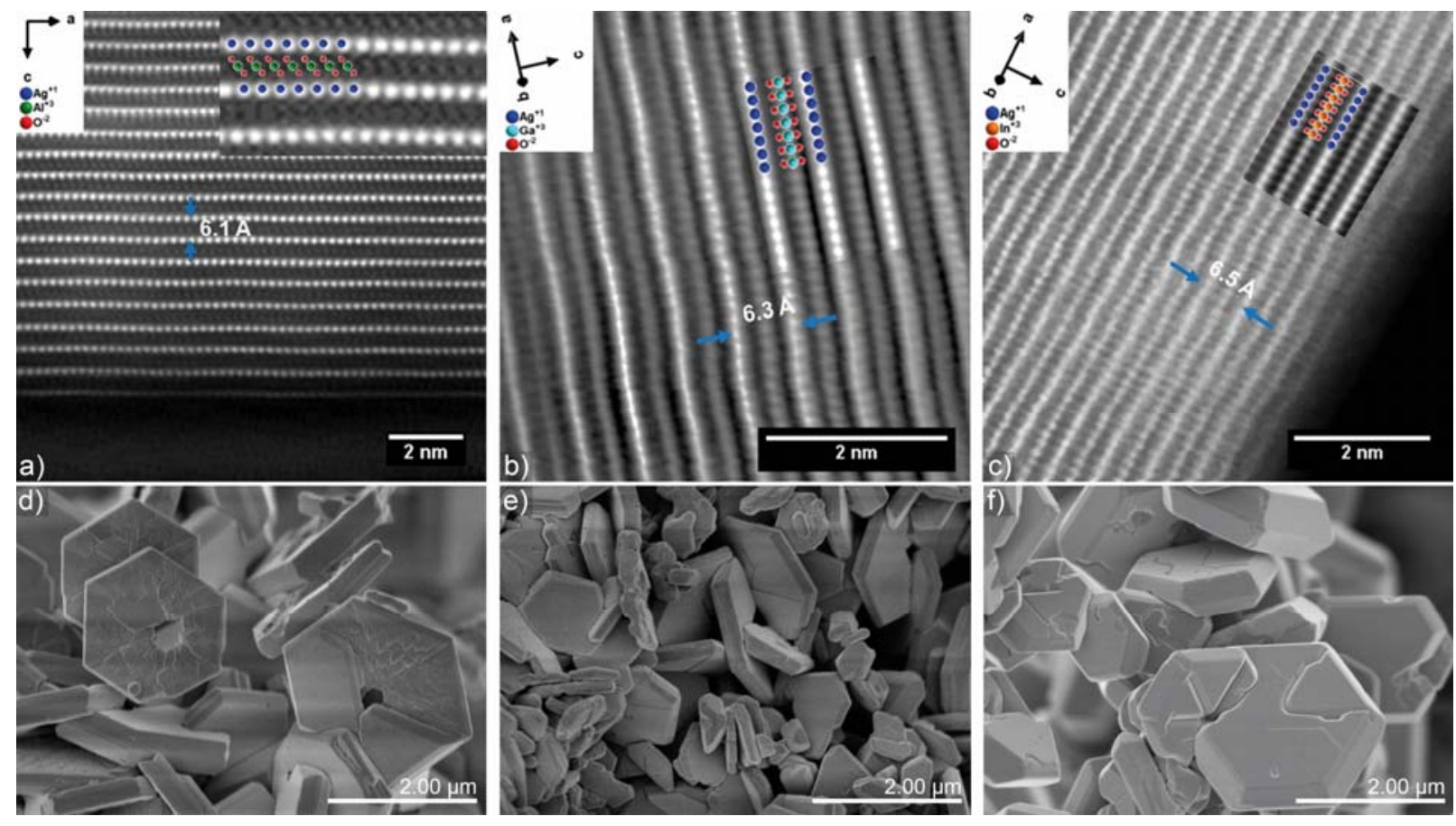

Figure 8: Atomic resolution HAADF images of the layered crystalline delafossite structures with inserted schematic models and Fourier filtered images for: a) $3 \mathrm{R}-\mathrm{AgAlO}_{2}$ along the [010] zone axis, b) $3 \mathrm{R}-\mathrm{AgGaO}_{2}$ along the [120] zone axis and c) 3R-AglnO 2 along the [120] zone axis. SEM images of $3 \mathrm{R}-\mathrm{AgAlO}_{2}$ (d), 3R-AgGaO 2 (e) and $3 \mathrm{R}-\mathrm{AgInO} 2$ (f). The blue arrows indicate the interplanar distance between (003) planes. The corresponding STEM-ABF images are presented in Figure S10.

For all Ag-delafossite compounds in this work, a distortion of the octahedral coordination geometry of the $B$-site ion is observed. To some extent, the $\mathrm{BO}_{6}$ octahedra are flattened along the $c$-axis. This observation is given in Figure $9 \mathrm{~b}$ as the ratio of intralayer (in the ab-plane) and interlayer O$O$ distances implying a similar degree of distortion for all samples. The OBO-angle deviates from the ideal octahedral angle of $90^{\circ}$. The experimental determined deviation is in the range of $7.0^{\circ}$ (Table 5), however no systematic trend for the $3 \mathrm{R}-\mathrm{AgBO}_{2}$ samples can be deduced, since all values lie well within $3 E S D\left(0.5^{\circ}\right)$. Consequently, a similar deformation is observed for the $\mathrm{OAgB}_{3}$ tetrahedral moieties (Figure 12c). It may be noted that the slope of the $B-O$ distances over the corresponding $B$ radii red line in Figure $9 a$ ) is almost exactly 1 , which means that the simple "hard sphere" model works very well for the $B-\mathrm{O}$ interaction, in contrast to the $\mathrm{Ag}-\mathrm{O}$ bonding. 

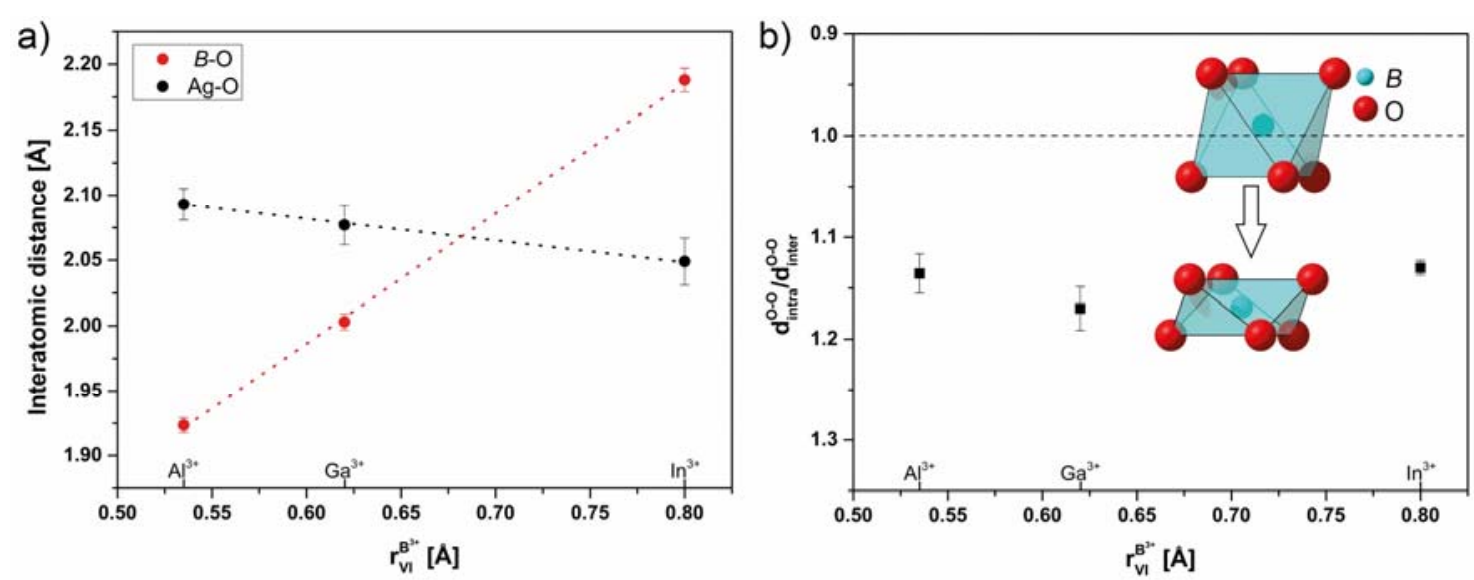

Figure 9: Trend of interatomic distances $\mathrm{B}-\mathrm{O}$ and $\mathrm{Ag}-\mathrm{O}(\mathrm{a})$ and the deformation of the $\mathrm{BO}_{6}$ octahedra (b) as a function of the 6-coordinate Shannon $\mathrm{B}^{3+}$ radii $\left(\mathrm{rvl}^{\mathrm{B} 3+}\right)$. Error bars of 3ESD (estimated standard deviations) are given for interatomic distances. A ratio for the intralayer O-O distance $\left(\mathrm{d}_{\text {intra }}{ }^{\mathrm{O}-\mathrm{O}}\right)$ and interlayer $\mathrm{O}-\mathrm{O}$ distance $\left(\mathrm{d}_{\text {inter }}{ }^{\mathrm{O}-\mathrm{O}}\right)$ greater than one reveals flattening of the $\mathrm{BO}_{6}$ octahedra along the c-axis as schematically shown.

According to the PDOS analysis, as expected, the formally empty $B$ states $\left(s^{0} p^{0}\right)$ mainly contribute to the conduction band, which hybridize with the O-p and Ag-d states (Figure 10). The position of the conduction band is steered by the selected group $13 \mathrm{~B}$-site atom. Going from $\mathrm{B}$ : Al to In, increasing contribution of the $s$ states on the lower energy side of the conduction band appear (olive green curves in Figure 10). This leads to a stepwise decrease in the calculated energetic gap between valence band and conduction band and an increase in covalent character with increasing size (respectively softness) of the $B$-site atom.

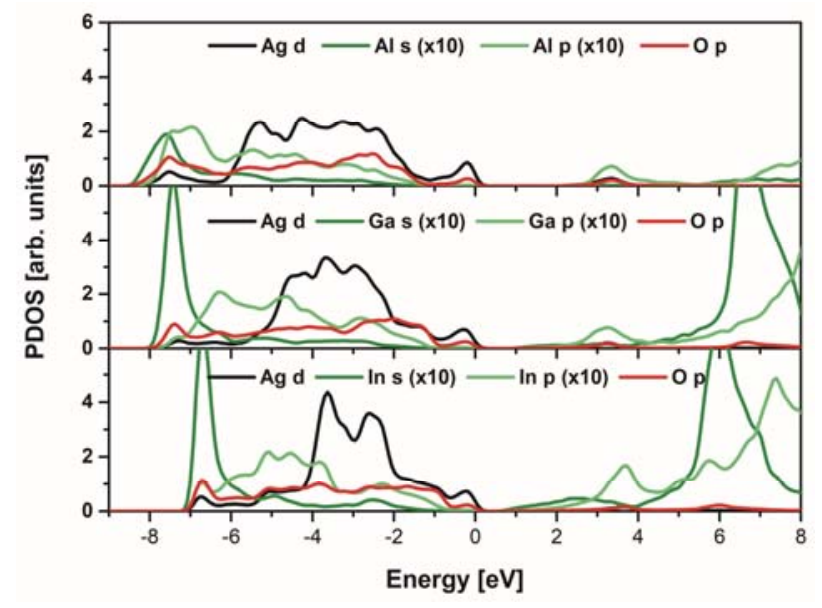

Figure 10: The projected density of states for $3 \mathrm{R}-\mathrm{AgAlO}_{2}$ (top panel), $3 \mathrm{R}-\mathrm{AgGaO}$ (middle panel) and $3 \mathrm{R}-\mathrm{AgInO} \mathrm{I}_{2}$ (bottom panel) obtained using the SCAN functional. 
Table 5: Rietveld refined and ab-initio calculated lattice parameters, z-position of oxygen, selected interatomic distances and angular deviation of $\mathrm{BO}_{6}$ in $3 \mathrm{R}-\mathrm{AgBO}_{2}\left(\mathrm{~B}: \mathrm{Al}, \mathrm{Ga}, \mathrm{In}\right.$ ) along with experimental results from Ref. ${ }^{[9,12]}$. In addition, the effective ionic Shannon radii are given for the $B$-site ions featuring a coordination number of six. In addition, the ionic radius of $\mathrm{Ag}_{\|}{ }^{+}$is $0.67 \AA$ and $\mathrm{OIv}^{2-:} 1.35 \AA^{[2 \mathrm{e}]}$. For the $3 \mathrm{R}-\mathrm{AgBO}_{2}$ polytype, the atomic fractional coordinates are $\mathrm{Ag}(3 \mathrm{a})(0,0,0), \mathrm{B}(3 \mathrm{~b})(0,0,0.5)$ and $\mathrm{O}(6 \mathrm{c})(0,0, \mathrm{z})$. Lattice constant a is equal to $\mathrm{d}(\mathrm{Ag}-\mathrm{Ag})[\AA]$.

\begin{tabular}{|c|c|c|c|c|c|c|c|}
\hline Sample & $a[\AA]$ & $c[\AA]$ & $z(O) / c$ & $\mathrm{~d}(\mathrm{Ag}-\mathrm{O})[\AA]]$ & $\mathrm{d}(B-O)[\AA]]$ & $\left.\Delta(\mathrm{O}-B-\mathrm{O})[]^{[}\right]^{[\mathrm{a}]}$ & $\left.\mathrm{rVI}^{\mathrm{B} 3+}[\AA \AA \AA]\right]^{[2 \mathrm{e}]}$ \\
\hline $3 \mathrm{R}-\mathrm{AgAlO}_{2}$ & & & & & & & 0.535 \\
\hline Rietveld refined & $2.8870(2)$ & $18.3161(3)$ & $0.1143(2)$ & $2.093(4)$ & $1.9236(19)$ & $7.25(13)$ & \\
\hline Ref. ${ }^{[12]}$ & $2.890(2)$ & $18.27(2)$ & & & & & \\
\hline \multicolumn{8}{|l|}{ Calculated } \\
\hline LDA & 2.84 & 18.32 & 0.11559 & 2.11 & 1.89 & 7.58 & \\
\hline PBE & 2.92 & 18.81 & 0.11588 & 2.18 & 1.94 & 7.86 & \\
\hline SCAN & 2.88 & 18.32 & 0.11462 & 2.10 & 1.95 & 7.35 & \\
\hline $3 \mathrm{R}-\mathrm{AgGaO}_{2}$ & & & & & & & 0.620 \\
\hline Rietveld refined & $2.9909(2)$ & $18.5548(4)$ & $0.1120(2)$ & $2.077(5)$ & $2.003(2)$ & $6.59(15)$ & \\
\hline Ref. ${ }^{[12]}$ & $2.9889(2)$ & $18.534(2)$ & & & & & \\
\hline \multicolumn{8}{|l|}{ Calculated } \\
\hline LDA & 2.98 & 18.63 & 0.11286 & 2.10 & 1.99 & 6.92 & \\
\hline PBE & 3.03 & 18.79 & 0.11280 & 2.12 & 2.02 & 7.16 & \\
\hline SCAN & 2.98 & 18.58 & 0.11276 & 2.10 & 1.99 & 6.91 & \\
\hline $3 \mathrm{R}-\mathrm{AgInO}{ }_{2}$ & & & & & & & 0.800 \\
\hline Rietveld refined & $3.2768(2)$ & $18.8865(2)$ & $0.1085(3)$ & $2.049(6)$ & $2.188(3)$ & $6.99(17)$ & \\
\hline Ref. ${ }^{[9]}$ & $3.2768(7)$ & $18.8779(70)$ & $0.1100(4)$ & $2.0766(76)$ & $2.1734(37)$ & $7.851(164)$ & \\
\hline \multicolumn{8}{|l|}{ Calculated } \\
\hline LDA & 3.26 & 18.92 & 0.11018 & 2.08 & 2.16 & 7.74 & \\
\hline PBE & 3.34 & 19.11 & 0.11000 & 2.10 & 2.21 & 8.07 & \\
\hline SCAN & 3.27 & 18.91 & 0.10973 & 2.08 & 2.17 & 6.63 & \\
\hline
\end{tabular}

[a] Angular deviation from the ideal octahedral angle of $90^{\circ}$.

This trend is also reflected in the experimentally determined optical band gaps of the ternary silver oxides (3.2 eV (B: Al), $2.5 \mathrm{eV}(\mathrm{Ga})$ to $2.1 \mathrm{eV}(\mathrm{In})$ ). The band gaps are derived on the basis of Tauc plots, calculated from the measured diffuse reflectance spectra of $3 \mathrm{R}-\mathrm{AgBO} \mathrm{O}_{2}(\mathrm{~B}: \mathrm{Al}, \mathrm{Ga}, \mathrm{In})$ and given in Figure $\mathrm{S} 12$ and Table 4. The as-prepared powdered samples are of white $\left(3 \mathrm{R}-\mathrm{AgAlO} \mathrm{O}_{2}\right)$, olive green $\left(3 \mathrm{R}-\mathrm{AgGaO}_{2}\right)$ and orange $\left(3 \mathrm{R}-\mathrm{AgInO} \mathrm{O}_{2}\right)$ color. The experimental values are in qualitative agreement with the calculated values (Table 4). Furthermore, the conductivity of the samples was measured using the contact free Microwave Cavity Perturbation Technique (MCPT). In line with the decreasing band gaps, the conductivity increases within the series of $3 \mathrm{R}-\mathrm{AgBO} \mathrm{O}_{2}$ (B: Al, Ga, In) samples for larger $B$-site cations (Figure S12). Besides, as expected for semiconducting samples, the conductivity increases to higher temperatures (Table 4, 303 vs. $473 \mathrm{~K})$. 
To further study the effect of the $B$-site cation on the local environment, Raman spectroscopy was performed on the $3 \mathrm{R}-\mathrm{AgBO}_{2}(\mathrm{~B}: \mathrm{Al}, \mathrm{Ga}, \mathrm{In})$ samples. Factor group analysis was performed on the $3 R$-delafossite structure (space group $R-3 m$, No. 166) using the symmetry adapted modes (SAM) application of the Bilbao crystallographic server ${ }^{[29]}$. The primitive unit cell has four atoms, which gives rise to 12 normal modes. Accordingly, the total irreducible representation at the Brillouin zone center excluding both acoustic modes $\left(\Gamma_{\text {acoustic }}=A_{2 u}+E_{u}\right)$ gives two Raman active phonon modes $\left(\Gamma_{\text {Raman }}=A_{1 g}+E_{g}\right)$ and four IR active phonon modes $\left(\Gamma_{\mathbb{I}}=2 A_{2 u}+2 E_{u}\right)$. The A modes describe the movement along the $c$-axis, while $E$ modes do in the perpendicular direction in the ab-plane (Figure 11b). The measured Raman spectra are given in Figure 11a. The spectrum of $3 \mathrm{R}-\mathrm{AgAlO}_{2}$ (top trace) features two distinct bands at $711 \mathrm{~cm}^{-1}$ (calc. $714 \mathrm{~cm}^{-1}$ ) and $406 \mathrm{~cm}^{-1}$ (calc. $411 \mathrm{~cm}^{-1}$ ), which agrees well with the calculated Raman mode positions.

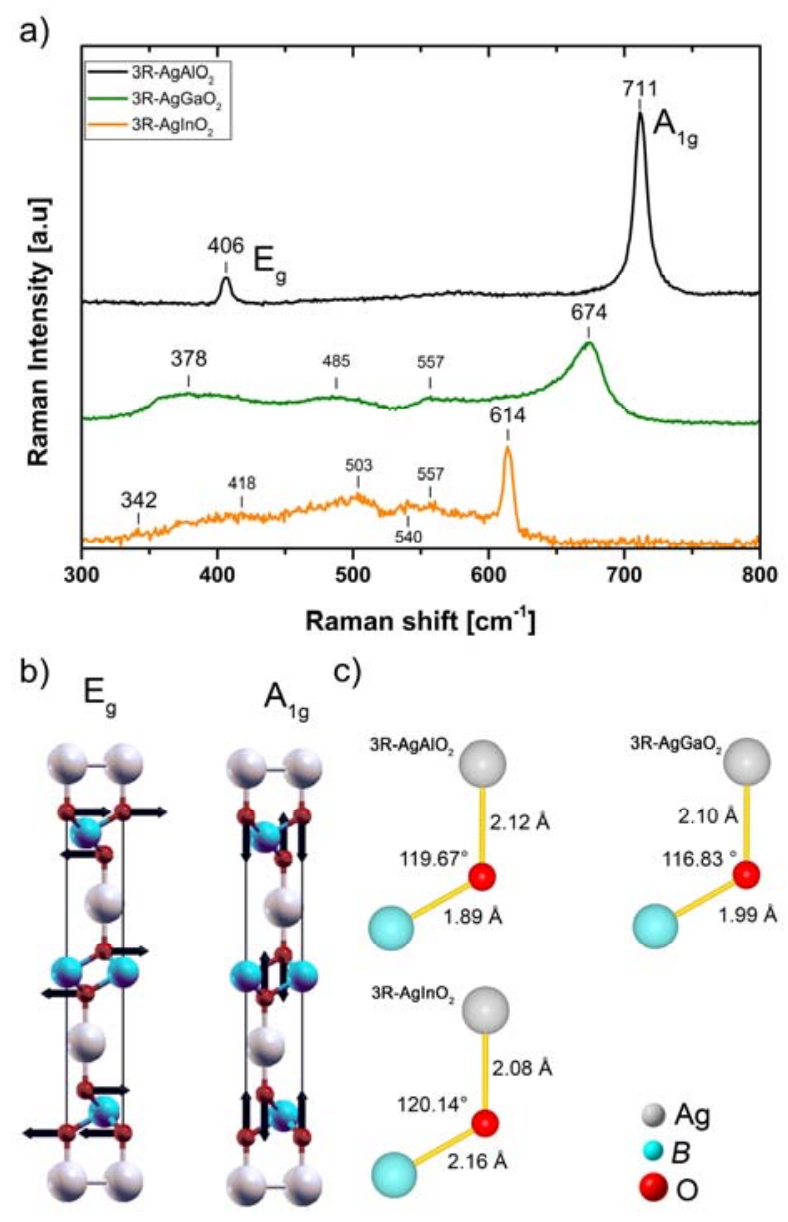

Figure 11: Raman spectra (a), corresponding displacement patterns (b) and calculated bond lengths and angles of the local environment of oxygen (c) for $3 \mathrm{R}_{-} \mathrm{AgBO}_{2}(\mathrm{~B}: \mathrm{Al}, \mathrm{Ga}, \mathrm{In})$.

The former could be assigned to the $A_{1 g}$ mode, which is associated to oxygen vibration along the hexagonal c-axis, in the direction of the Ag-O bond. The latter at $406 \mathrm{~cm}^{-1}$ is assigned to the double degenerate $E_{g}$ mode in the ab-plane (Figure 11b). Note that only oxygen contributes to both Raman active mode, since Ag and the group 13 element are stationary. Oxygen is in a distorted tetrahedral coordination with one $\mathrm{Ag}^{\prime}$ and three $\mathrm{B}^{\text {III }}$ (Figure 11c). The position of these bands is sensitive to the nature of the $B$-site ions. The intense $A_{1 g}$ mode shifts progressively to lower 
wavenumbers for $3 R-A g \mathrm{RaO}_{2}\left(674 \mathrm{~cm}^{-1}\right.$, calc. $\left.652 \mathrm{~cm}^{-1}\right)$ and $3 \mathrm{R}-\mathrm{AgInO}_{2}\left(614 \mathrm{~cm}^{-1}\right.$, calc. $618 \mathrm{~cm}^{-}$ 1). A similar gradual shift is observed for the lower wavenumber bending $E_{g}$ mode that is located at $378 \mathrm{~cm}^{-1}$ for $3 \mathrm{R}-\mathrm{AgGaO}_{2}$ (calc. $302 \mathrm{~cm}^{-1}$ ) and $342 \mathrm{~cm}^{1}$ for $3 \mathrm{R}-\mathrm{AgInO}_{2}$ (calc. $344 \mathrm{~cm}^{-1}$ ). As the $\mathrm{Ag}-\mathrm{O}$ distance remains almost constant in all samples $(2.10 \pm 0.02 \AA$, Figure $11 \mathrm{c})$, this indicates the frequency depends strongly on the nature of the $\mathrm{B}-\mathrm{O}$ bonding.

The delafossite Raman spectra should only feature two modes. However, for $B$ : Ga and In they deviate from the number of modes predicted by group theory and feature additional broad signals around $400-560 \mathrm{~cm}^{-1}$ located between $E_{g}$ and $A_{1 g}$. These weak modes become more apparent and complex along the series of samples. Their presence cannot be assigned to the trace impurities (Figure 7). Besides, they have been previously reported in the case of $B: \mathrm{Ga}\left(485 \mathrm{~cm}^{-1}\right.$ and $\left.557 \mathrm{~cm}^{-1}\right)^{[14,30]}$ and similar observations have been made for Cu-delafossites $(B$ : $\mathrm{Al}, \mathrm{Cr}, \mathrm{Fe}$, $\mathrm{Ga})^{[31]}$. To the best of the authors knowledge, no Raman measurements of $3 \mathrm{R}-\mathrm{Ag} \mathrm{InO} \mathrm{O}_{2}$ have been reported, so far. These low-intensity bands might originate from the distortion of the oxygen moieties or present defects (oxygen non-stoichiometry) as Raman spectroscopy is sensitive to the crystal symmetry and changes of the local structure.

\section{Thermal reactivity of $3 \mathrm{R}-\mathrm{AgBO}$}

In order to evaluate the suitability of these materials as heterogeneous catalyst precursors, the thermal behavior of all samples was investigated by STA/EGA techniques in Ar up to $1273 \mathrm{~K}$. The results are presented comparatively in the different panels of Figure 12. The individual patterns are given in Figure S14. Upon thermal treatment of $3 \mathrm{R}-\mathrm{AgAlO}{ }_{2}$ the release of $\mathrm{H}_{2} \mathrm{O}(\mathrm{m} / \mathrm{z} 18$, up to about $600 \mathrm{~K}$ ) is detected by EGA which is attributed to its desorption from the surface. The minor release of $\mathrm{CO}_{2}(\mathrm{~m} / \mathrm{z} 44$, up to $750 \mathrm{~K})$ might be correlated to the decomposition of incorporated carbonate species in the delafossite structure (Figure 12c). The ongoing temperature increase leads to the renewed release of $\mathrm{H}_{2} \mathrm{O}$, present as a broad signal centered around $906 \mathrm{~K}$. Its occurrence is attributed to the dehydration of hydroxyl group condensation from the hydroxylated metal oxide surfaces ${ }^{[32]}$. As the samples were prepared under hydrothermal synthesis conditions and not calcined prior to the STA. These processes account for a limited mass loss of about $0.2 \%$ (average of 3 measurements). Similar observations are made for $B: \mathrm{Ga}(0.4 \%$, Figure S14b) and In $(0.1 \%$, Figure S14c) as well. The ternary oxides decompose in a single endothermal (Figure 12b) main event, according to the given reaction:

$$
4 \mathrm{AgBO}_{2(\mathrm{~s})}(\mathrm{B}: \mathrm{Al}, \mathrm{Ga}, \mathrm{In}) \rightarrow 4 \mathrm{Ag}_{(\mathrm{s})}+2 \mathrm{~B}_{2} \mathrm{O}_{3(\mathrm{~s})}+\mathrm{O}_{2(\mathrm{~g})} \uparrow
$$

This event is located at $1075 \mathrm{~K}$ for the $3 \mathrm{R}-\mathrm{AgAlO}_{2}$ and coincides with a mass loss of $4.5 \%$ (due to oxygen release) which is close to the calculated value $(4.8 \mathrm{wt}$. \%). In the case of $3 \mathrm{R}-\mathrm{AgGaO}$ the decomposition is shifted to $960 \mathrm{~K}$, respectively $900 \mathrm{~K}$ for $3 \mathrm{R}-\mathrm{Ag}_{\mathrm{InO}}$ (Figure 12a). In both cases, the detected mass losses are in excellent agreement with the theoretic values (Table 4). Investigations for the verification of the proposed non-stoichiometry of the anion lattice were performed by temperature programmed oxidation experiments (TPO) in $0.25 \% \mathrm{O}_{2} / \mathrm{He}$. Despite the use of up to $1.5 \mathrm{~g} 3 \mathrm{R}-\mathrm{AgBO}_{2}$, no oxygen uptake could be observed from $298 \mathrm{~K}$ up to below the decomposition temperature (details see SI, Figure S16). The presence of elemental Ag and 
the respective $B$-site metal(III) oxide is verified for all samples after the STA by XRD analysis (Figure S14). In addition the endothermal DSC event detectable for all samples around $1239 \mathrm{~K}$ indicates the melting of $\mathrm{Ag}^{[33]}$.

According to Kandpal et al. the structural stability of the ternary oxides originates from the strong ionic character of the $B-O$ bonding interaction. ${ }^{4 h]}$ Thus, the observed trend towards lower decomposition temperatures along the series of group $13 B$-site atoms is in line with the expected lower attractive ionic $B-O$ interaction when going from the hard $A l$ to the softer In. Further, the thermal reactivity results of the $3 \mathrm{R}-\mathrm{AgBO} \mathrm{O}_{2}$ series show the potential temperature and application range of these materials as precursors, supports or catalysts under oxidizing conditions. The detailed investigation as catalytic material is beyond the scope of this manuscript.

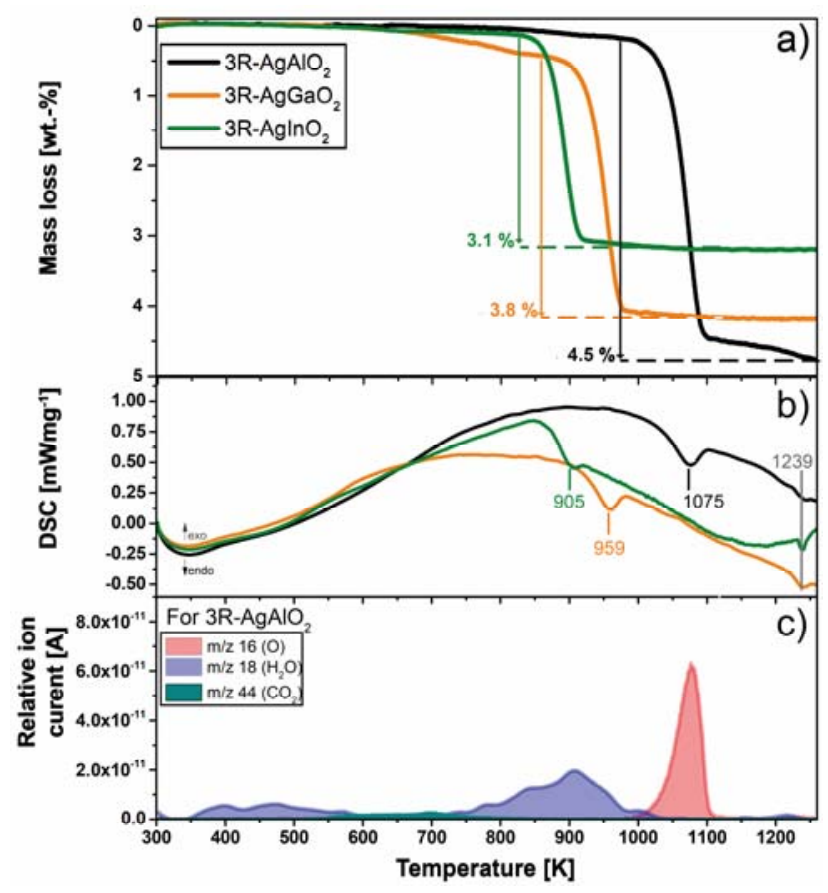

Figure 12: Simultaneous thermal analysis (STA) of $3 \mathrm{R}-\mathrm{AgBO}_{2}(\mathrm{~B}: \mathrm{Al}, \mathrm{Ga}, \mathrm{In}$ ) by TG (a), DSC (b) and EGA (c) in $\mathrm{Ar}$ atmosphere. For the sake of clarity, only the MS data (relative ion currents) for $B$ : Al is given in panel $\mathrm{C}$.

\section{Conclusions}

We herein report on the improved synthesis of $3 R-A g B O_{2}(B: A l, G a, I n)$. The frequently reported presence of an elemental Ag by-phase originates from the metastability of the delafossite phase under reaction conditions. Hence, the ternary Ag oxides represent the kinetically favored product making shorter hydrothermal synthesis times necessary. By optimizing the reaction parameters, the synthesis time requirements were successfully reduced by up to $90 \%$, obtaining high-purity products. By the selection of isoelectronic group 13 ions as $B$-site atoms, the structure and bonding situation were comparatively studied experimentally and by means of ab-inito calculations. Heavier $B$-site atoms lead to a pronounced unit cell expansion, reflected in longer $B$ $\mathrm{O}$ bonds and overall distorted coordination environments. In contrast, the Ag-O distance remains 
largely unchanged by the substitution. The nature of the $B-O$ bonding interaction changes qualitatively along the group 13 atoms $\mathrm{Al}, \mathrm{Ga}$ and In as indicated by the analysis of the electronic structure and supported by experimental evidences. Properties such as the (optical) band gap, contactless conductivity, energetic position of Raman modes and the thermal stability are strongly affected and decrease with increasing atom number/softness of the B-site atom. Besides, the variation of the B-site cation offers the possibility to adjust the material properties, potentially applied as catalytic material for oxidation reactions (precursor, support, catalyst) and optoelectronic devices.

\section{Experimental Section}

General: All reagents were purchased from commercial vendors and were used without further purification. Ultrapure water was taken from a Milli-Q water treatment system (Merck Millipore) and used for all given experiments.

Synthesis: In a typical reaction, 3R-AgAlO ${ }_{2}$ was prepared by the hydrothermal reaction $(1.8 \mathrm{~g}$ total mass) of $\mathrm{Ag}_{2} \mathrm{O}\left(0.957 \mathrm{~g}, 4.13 \mathrm{mmol}, 1.0 \mathrm{eq},>99 \%\right.$, Carl Roth, lot: 207258506) and $\alpha-\mathrm{Al}_{2} \mathrm{O}_{3}$ (0.843 g, $8.26 \mathrm{mmol}, 2.0 \mathrm{eq}, 99+, 40 \mathrm{~nm}$ APS, Chempur, lot: 29092015). The reactants were mixed in an agate mortar and placed in the $45 \mathrm{ml}$ PTFE-lined pressure vessel (Model 4744, Parr Instrument Company), which was then filled with $30 \mathrm{ml}$ of $0.9 \mathrm{~m} \mathrm{NaOH}$ solution $(\mathrm{NaOH}$ : $>99 \%$, Carl Roth, lot: 166238400). The pressure vessel was sealed and heated to the desired reaction temperature of $483 \mathrm{~K}$ with a rate of $5 \mathrm{Kmin}^{-1}$. The maximum temperature was held constant for $30 \mathrm{~h}$. After reaching room temperature, the pressure vessel was opened, and the polycrystalline product was recovered by filtration, followed by a deionized water rinse to remove any $\mathrm{NaOH}$ traces. The sample was washed several times until the conductivity of the washing medium was below $0.5 \mathrm{mScm}^{-1}$. Afterwards, the sample was dried at $333 \mathrm{~K}$ for $12 \mathrm{~h}$. To minimize any photochromic decomposition of the $3 \mathrm{R}-\mathrm{AgAlO}$, the samples were kept away from light.

$3 \mathrm{R}-\mathrm{AgGaO}_{2}$ and $3 \mathrm{R}-\mathrm{AgInO}{ }_{2}$ were prepared in a modified procedure. $3 \mathrm{R}-\mathrm{AgGaO}_{2}$ was prepared from $\mathrm{Ga}_{2} \mathrm{O}_{3}(1.11 \mathrm{~g}, 5.93 \mathrm{mmol}, 2.0 \mathrm{eq}, 99.999 \%$, Carl Roth, lot: 465236502$)$ and $\mathrm{Ag}_{2} \mathrm{O}$ (0.688 g, $2.97 \mathrm{mmol}, 1.0 \mathrm{eq},>99 \%$, Carl Roth, lot: 207258506) and the hydrothermal synthesis time was reduced to $10 \mathrm{~h}$. In the case of $3 \mathrm{R}-\mathrm{AgInO}$, equimolar ratios of $\ln _{2} \mathrm{O}_{3}(0.981 \mathrm{~g}, 3.53 \mathrm{mmol}, 1.0 \mathrm{eq}$, 99.999 \%, Carl Roth, lot: 033195971) and $\mathrm{Ag}_{2} \mathrm{O}$ (0.819 g, $3.53 \mathrm{mmol}, 1.0 \mathrm{eq}$, >99 \%, Carl Roth, lot: 207258506) were used.

Characterization: Powder X-ray diffraction (PXRD) data was recorded on a STOE STADI P transmission diffractometer using a primary focusing $\mathrm{Ge}$ monochromator for $\mathrm{Cu} \mathrm{Ka}_{1}$ radiation and a DECTRIS MYTHEN 1K position sensitive solid-state detector. The finely ground sample powders were fixed between two layers of thin polyacetate film with small amounts of X-ray amorphous grease before mounting. In addition, PXRD measurements were performed in BraggBrentano geometry on a D8 Advance II theta/theta diffractometer (Bruker AXS), using Ni filtered

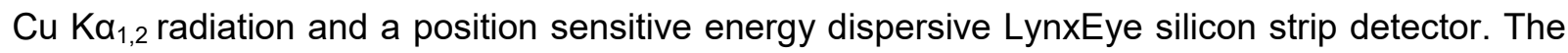
sample powder was filled into the recess of a cup-shaped sample holder, the surface of the powder bed being flush with the sample holder edge (front loading). Pattern fitting and phase analysis 
were performed by using the Rietveld method as implemented in the TOPAS software package (TOPAS version 5.0, 1999 - 2014 Bruker AXS)

Elemental analysis was performed by inductively coupled plasma atomic emission spectroscopy (ICP-OES). Each sample (58 - $83 \mathrm{mg}$ ) was dissolved in a mixture of $100 \mathrm{mg}$ LiF (Merck), $5.0 \mathrm{ml}$ $\mathrm{H}_{2} \mathrm{O}$ and $5.0 \mathrm{~m} \mathrm{HNO}_{3}(65 \%$, suprapur,Merck) while heating to $503 \mathrm{~K}$ for $2 \mathrm{~h}$ using a Multiwavve PRO microwave (Anton Parr). The obtained solutions were diluted to $50 \mathrm{ml}$ with $\mathrm{H}_{2} \mathrm{O}$. From this solution, a $100 \mu \mathrm{l}$ sample was mixed with $65 \mathrm{\mu l} \mathrm{HNO}_{3}$ (65\%, suprapur, Merck) and further diluted to $13 \mathrm{ml}$ with $\mathrm{H}_{2} \mathrm{O}$ prior to the analysis. The analysis was performed using an Optima 8300 optical emission spectrometer (Perkin Elmer) in axial mode. For the evaluation, commercial multi-element standards (Certipur,Merck) were used. Data analysis was performed using the Syngistix software for ICP (Perkin Elmer).

The Brunauer-Emmett-Teller (BET) surface area ${ }^{[34]}$ was calculated on basis of $\mathrm{N}_{2}$ physisorption isotherms which were obtained at liquid nitrogen temperature $(77 \mathrm{~K})$ using an Autosorb-6B2-KR (Quantachrome). Prior to measurement, the samples had been degassed at $373 \mathrm{~K}$ using an Autosorb Degasser setup (Quantachrome).

UV-vis Diffuse reflectance spectroscopy (UV-Vis DRS) was performed with a Lambda 650 UV Vis spectrometer (Perkin Elmer) equipped with a Praying Mantis ${ }^{\mathrm{TM}}$ diffuse reflectance attachment (DRP-SAP, Harrick). Data were recorded in reflectance percentage and afterwards converted to Kubelka-Munk function to determine the optical band gap. A baseline spectrum in the range of $800-300 \mathrm{~nm}$ of $\mathrm{BaSO}_{4}$ (Merck, Lot: K44813948409) as white standard was collected prior to the experiment. $3 \mathrm{R}-\mathrm{AgBO}_{2}(\mathrm{~B}: \mathrm{Ga}, \mathrm{In})$ samples were diluted with $\mathrm{BaSO}_{4}$ prior to the measurement.

Raman measurements were conducted using a confocal microscope system (S\&I Spectroscopy \& Imaging $\mathrm{GmbH}$ ) with a monochromator $(750 \mathrm{~mm}$ focal length, Princeton Instruments) at ambient temperature. Prior to the measurement calibration of the spectrometer frequency was performed by using a Si wafer $\left(520.7 \pm 0.5 \mathrm{~cm}^{-1}\right)$. All samples were excited by a $532 \mathrm{~nm}$ laser (Samba CW DPSSL, Cobolt) with the laser power lower than $0.5 \mathrm{~mW}\left(600 \mathrm{gr} / \mathrm{mm}\right.$, resolution: $\left.1.4-1.0 \mathrm{~cm}^{-1}\right)$. Scattered light signals were monitored by a back-illuminated CCD detector (PyLoN:2K, Princeton Instruments).

Conductivity measurements of the powdered samples were performed using the contact free Microwave Cavity perturbation technique (MCPT) in the setup published previously. ${ }^{[35]}$ The measurements were performed at two temperatures, first $473 \mathrm{~K}$ and then at $303 \mathrm{~K}$, and with an applied flow of $10 \mathrm{~mL} / \mathrm{min} \mathrm{N}_{2}$. The temperature of the cavity used was kept at $293 \mathrm{~K}$. The $\mathrm{TM}_{010}$ mode of an S-band resonator (resonance frequency of $3.26 \mathrm{GHz}$ ) was used for all measurements. The reflection coefficient was measured in a frequency range of 3.23 to $3.28 \mathrm{GHz}$ while scanning 20001 points using an IFBW of $500 \mathrm{~Hz}$. Three such measurements were averaged to give one data point, which was fit to determine the quality factor using Kajfez' algorithm. ${ }^{[36]}$ Ten data points were averaged to result in average quality factors. From the quality factors of measurements with and without sample, the conductivities were determined, taking into account the crystallographic densities of the compounds to account for the filling fraction of the powders in the MCPT sample holder. 
Simultaneous thermal analysis (STA) measurements (TG/DSC) were performed using a STA 449 C Jupiter thermoanalyzer (Netzsch) under a controlled gas atmosphere (Ar, $\left.100 \mathrm{mlmin}^{-1}\right)$. The evolved gases are monitored by a quadrupole mass spectrometer (QMS200 Omnistar, Balzers) coupled to STA via a quartz capillary heated to $313 \mathrm{~K}$. Each measurement was performed with approximately $20 \mathrm{mg}$ sample heating at $5 \mathrm{Kmin}^{-1}$ to $1273 \mathrm{~K}$. Upon cooling to room temperature, the residual powder was further analyzed by XRD analysis. All data were analyzed including TG and DSC curve smoothing using the NETZSCH Proteus Thermal Analysis software package (Version 6.10).

Scanning electron microscopy (SEM) images were taken on a S-4800 SEM (Hitachi) equipped with a field emission gun (FEG) system. The sample was dispersed on a tape of conductive carbon (Plano). The SEM was operated at low accelerating voltage $(1.5 \mathrm{kV})$ for increased resolution of the surface features of the sample. Elemental analysis was performed at elevated accelerating voltages $(20 \mathrm{kV})$ using an energy dispersive X-ray spectroscopy SDD (silicon drift detector, Bruker) connected to the SEM.

For transmission electron microscopy (TEM) analysis the samples were examined in the double Cs corrected microscope under an accelerating voltage of $200 \mathrm{keV}$ (JEM-ARM200F, JEOL). HR STEM images were acquired with spot size $8 \mathrm{C}$, condenser aperture of $30 \mu \mathrm{m}$, and camera length of $2 \mathrm{~cm}$. For the imaging a Gatan high-angle annular dark field (HAADF) and an annular brightfield $(A B F)$ detector were used. All $3 \mathrm{R}-\mathrm{AgBO}_{2}(\mathrm{~B}: \mathrm{Al}, \mathrm{Ga}, \mathrm{In})$ samples were prepared by the standard cross-section method.

X-ray photoelectron spectroscopy (XPS) was measured with a monochromatic Al $\mathrm{K}_{\alpha}$ source (SPECS XR 50) and a hemispherical analyzer (SPECS Phoibos-Has 3500). The pelletized samples were mounted on a sapphire sample holder, between a stainless-steel back-plate and a lid with a $6 \mathrm{~mm}$ hole. All XP spectra were collected in normal photoemission mode with $\mathrm{E}_{\text {pass }}=$ $20 \mathrm{eV}$. Charging of the samples by 3-6 eV was observe during the acquisition of the spectra. All spectra were aligned using the Fermi edge with an accuracy of $0.1 \mathrm{eV}$

All density functional theory calculations were performed using the Quantum ESPRESSO package version 6.3 $3^{[37]}$ using the Perdew Wang LDA ${ }^{[38]}$, Perdew Burke Ernzerhof GGA (PBE) ${ }^{[39]}$, and the Strongly Constrained and Appropriately Normed Semilocal Density Functional (SCAN) $)^{[40]}$ functionals as noted in the text. Norm conversing pseudopotentials were employed with a planewave basis set using a kinetic energy cutoff of $120 \mathrm{Ry}$ and a 6x6x1 k-point mesh for the crystallographic unit cell; a $12 \times 12 \times 2$ mesh was used to generate PDOS plots. The cell shape/volume and ionic positions were optimized for $3 \mathrm{R}-\mathrm{AgBO}_{2}(\mathrm{~B}: \mathrm{Al}, \mathrm{Ga}, \mathrm{In})$ starting from the published crystal structure of $3 \mathrm{R}-\mathrm{AgInO}_{2}$ (ICSD entry $202429^{[9]}$ ). The IR and Raman spectra were calculated at the $\Gamma$-point using LDA by way of density functional perturbation theory as implemented in the Phonon package ${ }^{[37]}$.

\section{Acknowledgements}

The authors thank J. Allan for XRD and TG/DSC/EG measurements, M. Hashagen and J. Plagemann for $\mathrm{N}_{2}$ physisorption measurements, W. Frandsen and D. Ivanov for SEM and EDX measurements and Dr. Y. Wang for Raman measurements. We thank Höchstleistungszentrum 
Stuttgart (HLRS) for access to the supercomputer HazelHen. This work was conducted in the framework of the BasCat collaboration between BASF SE, TU Berlin, $\mathrm{FHI}$, and the cluster of excellence "Unified Concepts in Catalysis" (UniCat www.unicat.tu-berlin.de).

\section{Conflict of interest}

The authors declare no conflict of interest.

Keywords: Ag-delafossite $\cdot \mathrm{AgAlO}_{2} \cdot \mathrm{AgGaO}_{2} \cdot \mathrm{AgInO}_{2} \cdot$ Hydrothermal synthesis

S. Friedel, S. C. R. Acad. Sci. Paris 1873, 77, 211.

[2] a) R. D. Shannon, C. T. Prewitt, D. B. Rogers, Inorg. Chem. 1971, 10, 719-723; b) W. C. Sheets, E. Mugnier, A. Barnabé, T. J. Marks, K. R. Poeppelmeier, Chem. Mat. 2006, 18, 7-20; c) W. C. Sheets, E. S. Stampler, M. I. Bertoni, M. Sasaki, T. J. Marks, T. O. Mason, K. R.

Poeppelmeier, Inorg. Chem. 2008, 47, 2696-2705; d) D. Y. Shahriari, N. Erdman, U. T. M. Haug, M. C. Zarzyczny, L. D. Marks, K. R. Poeppelmeier, J. Phys. Chem. Solids 2003, 64, 1437-1441; e) R. Shannon, Acta Cryst. 1976, A32, 751-767.

[3] H. Kawazoe, M. Yasukawa, H. Hyodo, M. Kurita, H. Yanagi, H. Hosono, Nature 1997, 389, 939-942.

[4] a) S. Ouyang, H. Zhang, D. Li, T. Yu, J. Ye, Z. Zou, J. Phys. Chem. B 2006, 110, 1167711682; b) S. Ouyang, N. Kikugawa, D. Chen, Z. Zou, J. Ye, J. Phys. Chem. C 2009, 113, $1560-$ 1566; c) S. Kumar, H. C. Gupta, Comput. Theor. Chem. 2011, 977, 78-85; d) K. Mukesh, Z. Hanyue, P. Clas, Semicond. Sci. Technol. 2013, 28, 065003; e) H. F. Jiang, C. Y. Gui, Y. Y. Zhu, D. J. Wu, S. P. Sun, C. Xiong, X. B. Zhu, Journal of Alloys and Compounds 2014, 582, 6468; f) M.-S. Miao, S. Yarbro, P. T. Barton, R. Seshadri, Phys. Rev. B 2014, 89, 045306; g) M. F. lozzi, P. Vajeeston, R. Vidya, P. Ravindran, H. Fjellvag, RSC Advances 2015, 5, 1366-1377; h) H. C. Kandpal, R. Seshadri, Solid State Sci. 2002, 4, 1045-1052.

[5] a) T. Otabe, K. Ueda, A. Kudoh, H. Hosono, H. Kawazoe, Appl. Phys. Lett. 1998, 72, 1036-1038; b) K. A. Vanaja, R. S. Ajimsha, A. S. Asha, M. K. Jayaraj, Appl. Phys. Lett. 2006, 88, 212103; c) H. Kawazoe, H. Yanagi, K. Ueda, H. Hosono, MRS Bulletin 2011, 25, 28-36.

[6] a) Y. Maruyama, H. Irie, K. Hashimoto, J. Phys. Chem. B 2006, 110, 23274-23278; b) H. Dong, Z. Li, X. Xu, Z. Ding, L. Wu, X. Wang, X. Fu, Appl. Catal., B 2009, 89, 551-556.

[7] B. U. Köhler, M. Jansen, Z. Anorg. Allg. Chem. 1986, 543, 73-80.

[8] M. A. Marquardt, N. A. Ashmore, D. P. Cann, Thin Solid Films 2006, 496, 146-156.

[9] B. U. Köhler, M. Jansen, J. Solid State Chem. 1987, 71, 566-569.

[10] G. Brachtel, M. Jansen, Cryst. Struct. Com. 1981, 10, 173-174.

[11] D. R. Lide, CRC handbook of chemistry and physics : a ready-reference book of chemical and physical data, CRC Press, Boca Raton, Fla., 2009.

[12] R. D. Shannon, D. B. Rogers, C. T. Prewitt, Inorg. Chem. 1971, 10, 713-718.

[13] W. J. Croft, N. C. Tombs, R. E. England, Acta Crystallogr. 1964, 17, 313. 
[14] M. Akhtar, M. Menon, M. Sunkara, G. Sumanasekera, A. Durygin, J. B. Jasinski, J. Alloys Compd. 2015, 641, 87-92.

[15] a) W. T. A. Harrison, T. M. Nenoff, T. E. Gier, G. D. Stucky, Inorg. Chem. 1993, 32, 2437-2441; b) P. Halasyamani, M. J. Willis, C. L. Stern, K. R. Poeppelmeier, Inorganica Chim. Acta 1995, 240, 109-115.

[16] D. Xiong, X. Zeng, W. Zhang, H. Wang, X. Zhao, W. Chen, Y.-B. Cheng, Inorganic Chemistry 2014, 53, 4106-4116.

[17] R. Albrecht, Angew. Chem. Int. Ed. Engl. 1985, 24, 1026-1040.

[18] W. L. Suchanek, M. M. Lencka, R. E. Riman, in Aqueous Systems at Elevated Temperatures and Pressures (Eds.: R. Fernández-Prini, A. H. Harvey), Academic Press, London, 2004, pp. 717-744.

[19] W. Gessner, Z. Anorg. Allg. Chem. 1968, 360, 247-258.

[20] D. J. Wesolowski, S. E. Ziemniak, L. M. Anovitz, M. L. Machesky, P. Bénézeth, D. A. Palmer, in Aqueous Systems at Elevated Temperatures and Pressures, Academic Press, London, 2004, pp. 493-595.

[21] R. Gout, G. Verdes, Eur. J. Mineral. 1993, 5, 215-218.

[22] a) D. A. Palmer, P. Bénézeth, D. J. Wesolowski, Geochim. Cosmochim. Acta 2001, 65, 2081-2095; b) P. Bénézeth, D. A. Palmer, D. J. Wesolowski, Geochim. Cosmochim. Acta 2001, $65,2097-2111$.

[23] a) S. Castet, J.-L. Dandurand, J. Schott, R. Gout, Geochim. Cosmochim. Acta 1993, 57, 4869-4884; b) W. L. Bourcier, K. G. Knauss, K. J. Jackson, Geochim. Cosmochim. Acta 1993, $57,747-762$.

[24] a) A. Wichainchai, P. Dordor, J. P. Doumerc, E. Marquestaut, M. Pouchard, P. Hagenmuller, A. Ammar, J. Solid State Chem. 1988, 74, 126-131; b) R. N. Attili, R. N. Saxena, A. W. Carbonari, J. Mestnik Filho, M. Uhrmacher, K. P. Lieb, Physical Review B 1998, 58, 25632569.

[25] H. L. Johnston, F. Cuta, A. B. Garrett, J. Am. Chem. Soc. 1933, 55, 2311-2325.

[26] B. G. Pound, D. D. Macdonald, J. W. Tomlinson, Electrochim. Acta 1979, 24, 929-937.

[27] I. I. Diakonov, G. S. Pokrovski, P. Bénézeth, J. Schott, J.-L. Dandurand, J. Escalier, Geochim. Cosmochim. Acta 1997, 61, 1333-1343.

[28] L. C. A. Thompson, R. Pacer, J. Inorg. Nucl. Chem. 1963, 25, 1041-1044.

[29] E. Kroumova, M. I. Aroyo, J. M. Perez-Mato, A. Kirov, C. Capillas, S. Ivantchev, H. Wondratschek, Phase Transitions 2003, 76, 155-170.

[30] R. Nagarajan, N. Tomar, J. Solid State Chem. 2009, 182, 1283-1290.

[31] a) J. Pellicer-Porres, A. Segura, E. Martínez, A. M. Saitta, A. Polian, J. C. Chervin, B. Canny, Phys. Rev. B. 2005, 72, 064301; b) J. Pellicer-Porres, D. Martínez-García, A. Segura, P. Rodríguez-Hernández, A. Muñoz, J. C. Chervin, N. Garro, D. Kim, Phys. Rev. B. 2006, 74, 
184301; c) O. Aktas, K. D. Truong, T. Otani, G. Balakrishnan, M. J. Clouter, T. Kimura, G. Quirion, J. Phys. Condens. Matter. 2012, 24, 036003.

[32] a) G. E. Brown, Jr., V. E. Henrich, W. H. Casey, D. L. Clark, C. Eggleston, A. Felmy, D. W. Goodman, M. Gratzel, G. Maciel, M. I. McCarthy, K. H. Nealson, D. A. Sverjensky, M. F. Toney, J. M. Zachara, Chem Rev 1999, 99, 77-174; b) H. Knözinger, P. Ratnasamy, Catal. Rev. 1978, 17, 31-70.

[33] W. M. Haynes, CRC Handbook of Chemistry and Physics, 96 th ed., CRC Press, 2015.

[34] S. Brunauer, P. H. Emmett, E. Teller, J. Am. Chem. Soc. 1938, 60, 309-319.

[35] M. Eichelbaum, R. Stößer, A. Karpov, C.-K. Dobner, F. Rosowski, A. Trunschke, R. Schlögl, Phys. Chem. Chem. Phys. 2012, 14, 1302-1312.

[36] D. Kajfez, Q factor measurements using MATLAB, Artech House, Norwood, 2011.

[37] a) G. Paolo, B. Stefano, B. Nicola, C. Matteo, C. Roberto, C. Carlo, C. Davide, L. C. Guido, C. Matteo, D. Ismaila, C. Andrea Dal, G. Stefano de, F. Stefano, F. Guido, G. Ralph, G. Uwe, G. Christos, K. Anton, L. Michele, M.-S. Layla, M. Nicola, M. Francesco, M. Riccardo, P. Stefano, P. Alfredo, P. Lorenzo, S. Carlo, S. Sandro, S. Gabriele, P. S. Ari, S. Alexander, U. Paolo, M. W. Renata, J. Phys. Condens. Matter. 2009, 21, 395502; b) P. Giannozzi, O. Andreussi, T. Brumme, O. Bunau, M. B. Nardelli, M. Calandra, R. Car, C. Cavazzoni, D. Ceresoli, M. Cococcioni, N. Colonna, I. Carnimeo, A. D. Corso, S. d. Gironcoli, P. Delugas, J. R. A. DiStasio, A. Ferretti, A. Floris, G. Fratesi, G. Fugallo, R. Gebauer, U. Gerstmann, F. Giustino, T. Gorni, J. Jia, M. Kawamura, H. Y. Ko, A. Kokalj, E. Küçükbenli, M. Lazzeri, M. Marsili, N. Marzari, F. Mauri, N. L. Nguyen, H. V. Nguyen, A. Otero-de-la-Roza, L. Paulatto, S. Poncé, D. Rocca, R. Sabatini, B. Santra, M. Schlipf, A. P. Seitsonen, A. Smogunov, I. Timrov, T. Thonhauser, P. Umari, N. Vast, X. Wu, S. Baroni, J. Phys. Condens. Matter. 2017, 29, 465901.

[38] J. P. Perdew, Y. Wang, Phys. Rev. B 1992, 45, 13244-13249.

[39] J. P. Perdew, K. Burke, M. Ernzerhof, Phys. Rev. Lett. 1996, 77, 3865-3868.

[40] J. Sun, A. Ruzsinszky, J. P. Perdew, Phys. Rev. Lett. 2015, 115, 036402. 